\title{
Quasi-100 ky glacial-interglacial cycles triggered by subglacial burial carbon release
}

\author{
N. Zeng ${ }^{1,2}$ \\ ${ }^{1}$ Department of Atmospheric and Oceanic Science, University of Maryland, College Park, MD 20742-2425, USA \\ ${ }^{2}$ The Department of Geology and the Earth System Science Interdisciplinary Center, University of Maryland, College Park, \\ MD 20742-2425, USA
}

Received: 22 May 2006 - Published in Clim. Past Discuss.: 7 July 2006

Revised: 22 January 2007 - Accepted: 15 February 2007 - Published: 2 March 2007

\begin{abstract}
A mechanism is proposed in which climate, carbon cycle and icesheets interact with each other to produce a feedback that can lead to quasi-100 ky glacial-interglacial cycles. A central process is the burial and preservation of organic carbon by icesheets which contributes to the observed glacial-interglacial $\mathrm{CO}_{2}$ change (the glacial burial hypothesis, Zeng, 2003). Allowing carbon cycle to interact with physical climate, here I further hypothesize that deglaciation can be triggered by the ejection of glacial burial carbon when a major icesheet grows to sufficiently large size after a prolonged glaciation so that subglacial transport becomes significant. Glacial inception may be initiated by $\mathrm{CO}_{2}$ drawdown due to a relaxation from a high but transient interglacial $\mathrm{CO}_{2}$ value as the land-originated $\mathrm{CO}_{2}$ invades into deep ocean via thermohaline circulation and $\mathrm{CaCO}_{3}$ compensation. Also important for glacial inception may be the $\mathrm{CO}_{2}$ uptake by vegetation and soil regrowth in the previously ice-covered regions. When tested in a fully coupled Earth system model with comprehensive carbon cycle components and semiempirical physical climate components, it produced under certain parameter regimes self-sustaining glacial-interglacial cycles with durations of $93 \mathrm{ky}, \mathrm{CO}_{2}$ changes of $90 \mathrm{ppmv}$, temperature changes of $6^{\circ} \mathrm{C}$. Since the $100 \mathrm{ky}$ cycles can not be easily explained by the Milankovitch astronomical forcing alone, this carbon-climate-icesheet mechanism provides a strong feedback that could interact with external forcings to produce the major observed Quaternary climatic variations. It is speculated that some glacial terminations may be triggered by this internal feedback while others by orbital forcing. Some observable consequences are highlighted that may support or falsify the theory.
\end{abstract}

Correspondence to: N. Zeng

(zeng@atmos.umd.edu)

\section{Introduction}

Paleoclimatic evidence from ice cores, ocean sediments and other sources reveal oscillations in climate and atmospheric $\mathrm{CO}_{2}$ over the last million years, with major signals in 20, 41 and 100 ky (thousands of years) frequency bands (Hays et al., 1976; Petit et al., 1999; EPICA, 2004). While changes in solar radiation caused by perturbations to Earth's orbit appear to be directly responsible for the $20 \mathrm{ky}$ and $41 \mathrm{ky}$ cycles, a full explanation of the dominant $100 \mathrm{ky}$ cycles remains elusive (Imbrie et al., 1993a; Roe and Allen, 1999; Wunsch, 2004).

It is increasingly clear that internal feedbacks in the Earth's climate system play a major role in the $100 \mathrm{ky}$ cycles, whether it is pacemaked by orbital forcing or not. Atmospheric model simulations show that the $80-100 \mathrm{ppmv}$ lower $\mathrm{CO}_{2}$ is the dominant factor in producing about $5^{\circ} \mathrm{C}$ cooler glacial climate, with additional contribution from ice-albedo and other effects (Broccoli and Manabe, 1987; Lorius et al., 1990; Weaver et al., 1998). It is very difficult, if not impossible, to simulate the observed glacial cooling in comprehensive models without changing $\mathrm{CO}_{2}$ ( $\mathrm{Li}$ et al., 1998; Ridgwell et al., 1999).

The other half of the problem, i.e., explaining the glacialinterglacial atmospheric $\mathrm{CO}_{2}$ change given the observed climate change, has proven more challenging. A dozen or so distinctly different mechanisms have been proposed since low glacial $\mathrm{CO}_{2}$ was first observed in an Antarctic ice core nearly 30 years ago, but there is no widely accepted explanation (Broecker and Henderson, 1998; Archer et al., 2000; Sigman and Boyle, 2000). Well-balanced combination of scenarios could explain up to $60 \mathrm{ppmv}$ of the observed 90 ppmv change (Ridgwell, 2001). One might be content with such a degree of agreement, but the multiple constraints

Published by Copernicus GmbH on behalf of the European Geosciences Union. 
imposed by the impressively large quantity and high quality Quaternary paleoclimatic and geochemical data render it an unsolved problem (Archer et al., 2000; Crowley, 2002). Most previous studies on the glacial $\mathrm{CO}_{2}$ problem assumed equilibrium by focusing on the difference between glacial maximum and interglacial. Recent studies have emphasized the transient nature of glacial-interglacial cycles especially deglaciation (e.g., Ridgwell, 2001; Zeng, 2003; Koehler et al., 2005).

Understanding the glacial $\mathrm{CO}_{2}$ problem is emerging as the key in the 100 ky climate cycles (Shackleton, 2000; Ruddiman, 2003), and most likely the observed large glacialinterglacial climate changes may only be fully understood by considering carbon cycle and physical climate in an interactive way, rather than considering the two aspects separately.

However, carbon cycle has rarely been included in comprehensive models interactively. Although some simple models did, they often lacked specific underlying process with justifiable strength to generate the $100 \mathrm{ky}$ cycles. (e.g., Saltzman and Maasch, 1988; Gildor and Tziperman, 2001). Recently, two novel theories were proposed that centered on carbon-climate interaction (Paillard and Parrenin, 2004; Toggweiler et al., 2006). Both ideas are particularly noteworthy in that they hypothesize specific deglaciation triggering mechanisms in the Southern Ocean carbon cycle, one involving brine rejection, the other atmospheric westerly winds interacting with ocean stability.

The present work is similar to the above two proposals in its interactiveness, but it is a different mechanism driven by terrestrial carbon cycle and icesheet dynamics. It stems from the glacial burial hypothesis (Zeng, 2003) in which vegetation and soil carbon is buried and preserved under icesheets during glaciation, and released back into the atmosphere during deglaciation. Given the unconventional nature of this hypothesis and its apparent inconsistency with the established notion of a lower glacial land carbon storage, I will discuss the merit of this hypothesis, i.e., its potential role in answering the second half of the problem (explaining $\mathrm{CO}_{2}$ given the observed climate change) below in Sect. 2, before continue to present the interactive carbon-climate theory in the remainder of the paper.

\section{The glacial burial hypothesis and why terrestrial bio- sphere may be a helper in the glacial $\mathrm{CO}_{2}$ problem}

In a widely-held view, the glacial terrestrial carbon storage was smaller than at interglacial, based on marine ${ }^{13} \mathrm{C}$, pollenbased vegetation reconstruction and terrestrial carbon models (see Table 1 of Zeng, 2003, for a summary). The underlying processes include the smaller land surface area for vegetation growth due to the presence of large ice sheets (partially compensated for by exposed continental shelves), and the colder and drier glacial climate that was less conducive for vegetation growth. There is uncomfortably large uncertainty among these estimates, but the number $500 \mathrm{GtC}(1 \mathrm{GtC}$ is 1 gigaton or 1 petagram or $10^{15} \mathrm{~g}$ of carbon; hereafter Gt in accord with paleoclimate tradition) has established itself in the literature, corresponding to a $0.35 \%$ lower mean glacial ocean $\delta^{13} \mathrm{C}$ (Curry et al., 1988; Duplessy et al., 1988). Thus the regrowth (expansion) of the terrestrial biosphere at deglaciation is supposed to take $500 \mathrm{Gt}$ out of the atmosphere-ocean system. Since atmosphere $\mathrm{CO}_{2}$ increased by about $90 \mathrm{ppmv}$ (approximately $180 \mathrm{Gt}$ ) from glacial maximum to interglacial, the ocean would have to accommodate this additional terrestrial carbon increase, thus land is a burden for the ocean mechanisms if they are to explain the full amplitude of atmospheric $\mathrm{CO}_{2}$ increase.

In contrast, Zeng (2003) proposes that large amount of vegetation and soil carbon was buried and preserved under the icesheets during glaciation. Together with several other factors such as continental shelf carbon at lower sea level, the glacial burial hypothesis claims more storage (about $500 \mathrm{GtC}$ in a model simulation) of carbon on land during a glacial maximum that is preserved and released during the ensuing deglaciation, thus contributing to deglacial $\mathrm{CO}_{2}$ rise. For the ease of discussion, I will frequently refer to a scenario in which terrestrial biosphere stores more carbon at glaciation and releases it at deglaciation a "helper" scenario, while the traditional view of a deglacial increase in terrestrial carbon pool is termed the "burden" scenario (above).

If land releases $500 \mathrm{Gt}$ during deglaciation (helper), it would produce 15 ppmv (i.e., about $6 \%$ of the $500 \mathrm{Gt}$ ) increase in atmospheric $\mathrm{CO}_{2}$ after the oceanic buffering effects' of deep ocean invasion and $\mathrm{CaCO}_{3}$ compensation equilibrize with the atmosphere (e.g., Sigman and Boyle, 2000). However, since the $\mathrm{CaCO}_{3}$ compensation timescale (about $8000 \mathrm{y}$ ) is comparable to the deglacial timescale on which land-ocean carbon transfer takes place, a $500 \mathrm{Gt}$ ocean-land carbon transfer leads to about $30 \mathrm{ppmv}(12 \%)$ increase in atmospheric $\mathrm{CO}_{2}$ (Zeng, 2003). Thus active ocean mechanisms only need to account for $60 \mathrm{ppmv}$ atmospheric $\mathrm{CO}_{2}$ increase. In contrast, if land takes up $500 \mathrm{Gt}$ (burden), the ocean mechanisms would have to explain an additional $30 \mathrm{ppmv}$, a total of $120 \mathrm{ppmv}$ increase in the atmosphere (Ridgwell, 2001; Koehler et al., 2005). Thus, a land helper would enable the active oceanic mechanisms such as changes in sea surface temperature and carbonate system to explain comfortably the full amplitude of the observed $\mathrm{CO}_{2}$ change. However, such a different terrestrial scenario would require the reexamination of a large amount of observations and theoretical ideas.

\subsection{Oceanic and atmospheric ${ }^{13} \mathrm{C}$ and ${ }^{14} \mathrm{C}$}

One prominent example is the marine $\delta^{13} \mathrm{C}$ records that suggest about $500 \mathrm{Gt}$ terrestrial carbon storage increase from glacial maximum to interglacial, inferred from an average $0.35 \%$ o lower glacial oceanic $\delta^{13} \mathrm{C}$ assuming a terrestrial $\delta^{13} \mathrm{C}$ signature of $-25 \%$ (Shackleton, 1977; Curry et al., 
1988; Duplessy et al., 1988; Crowley, 1995). However, such interpretation of benthic foraminiferal $\delta^{13} \mathrm{C}$ change can be complicated by many factors (Lea et al., 1999). There is a large error bar in the $-0.35 \%$ mean value due to these factors and the sparseness of the data especially over the large Pacific Ocean (Matsumoto and Lynch-Stieglitz, 1999).

More importantly, recent advances suggest the existence (at least possibility) of alternative explanations that either reduce the magnitude, do not require a lower glacial terrestrial carbon storage or even reverse the direction. I highlight three possibilities here:

1. The higher surface carbonate ion due to lower glacial atmospheric $\mathrm{CO}_{2}$ may directly influence surface (Spero et al., 1997) and possibly benthic (Lea et al., 1999) foraminiferal $\delta^{13} \mathrm{C}$ value, so that the observed lower glacial ocean $\delta^{13} \mathrm{C}$ values can be explained without input from light terrestrial carbon.

2. A more stratified glacial ocean (Toggweiler, 1999) would reduce the "range of influence" of the negative deep ocean $\delta^{13} \mathrm{C}$ values. Because the surface ocean tends to differ little between the Holocene and the last glacial maximum (LGM) (even higher $\delta^{13} \mathrm{C}$ in the N. Atlantic) (e.g., Fig. 8 of Matsumoto and LynchStieglitz, 1999; and Fig. 1 of Toggweiler et al., 2006) so that the global mean $\delta^{13} \mathrm{C}$ may be smaller than $-0.35 \%$, thus smaller inferred terrestrial carbon change.

3. A terrestrial carbon release at deglaciation may offer more straightforward explanation to a number of perplexing issues such as the deglacial minimum and the transient behavior observed in the atmospheric and surface ocean $\delta^{13} \mathrm{C}$ records (Smith et al., 1999; Spero and Lea, 2002). Indeed, recent data from EPICA (Leuenberger et al., 2005) support the earlier results of Marino et al. (1992) and Smith et al. (1999) in the deglacial minimum in atmospheric $\delta^{13} \mathrm{C}$, a natural outcome of a terrestrial light carbon input during deglaciation (see Fig. 9 of Zeng, 2003). These authors attempted (albeit vaguely) to explain this deglacial transient behavior based on changes in the ocean, but they have not been carefully quantified in models, and a terrestrial input provides a simpler explanation. In contrast, such transient behavior had been largely ignored in earlier glacial $\mathrm{CO}_{2}$ studies, and sometimes the low $\delta^{13} \mathrm{C}$ values at deglaciation may have been inadvertently averaged into the glacial mean value in low-resolution data.

Another interesting consequence of a deglacial terrestrial carbon input is that it would drive down atmospheric ${ }^{14} \mathrm{C}$ because the carbon from previous interglacial (about $100 \mathrm{ky}$ old) would be radioactively "dead", i.e., containing practically no ${ }^{14} \mathrm{C}$ due to the short life time (half-life 5730 years) of ${ }^{14} \mathrm{C}$. Also importantly, in a more realistic picture, part of the burial carbon pool will be younger than $100 \mathrm{ky}$ because of the decay and regrowth of vegetation in response to icesheet advance and shrinking on sub-100 ky cycles (next subsection). However, given that the $20 \mathrm{ky}$ and $41 \mathrm{ky}$ cycles are also significantly longer than ${ }^{14} \mathrm{C}$ half-life, a large part of this carbon pool would be ${ }^{14} \mathrm{C}$-dead at deglaciation.

If $500 \mathrm{Gt}{ }^{14} \mathrm{C}$-dead carbon is transferred from land to atmosphere instantaneously at deglaciation, this will lead to a change in atmospheric $\Delta^{14} \mathrm{C}$ of about $-500 \%$ o. If it is released uniformly over a period of $10 \mathrm{ky}$, the $\Delta^{14} \mathrm{C}$ decrease will be about $100-200 \%$, a discernable signal. It is not clear how good the "uniform" assumption is as both subglacial transport and icesheet retreat should be somewhat episodic, but these numbers nonetheless give a first-order estimate. A glance at the observed atmospheric ${ }^{14} \mathrm{C}$ over the last $50 \mathrm{ky}$ (e.g., Hughen et al., 2004) shows that ${ }^{14} \mathrm{C}$ variations are dominated by production rate, although it clearly contains other information, possibly related to changes in the North Atlantic deep water formation (Hughen et al., 2000; Laj et al., 2002). A terrestrial signal during last deglaciation thus offers an alternative or complementary explanation of changes such as the $\Delta^{14} \mathrm{C}$ decrease between $20 \mathrm{ka}$ (thousands of years before present) and $10 \mathrm{ka}$ that is more rapid than predicted by production rate alone (Fig. 7 of Laj et al., 2002 and Fig. 4 of Hughen et al., 2004).

Another important constraint is $\mathrm{CaCO}_{3}$ dissolution events at deglaciation which also poses a challenge to the case for a land helper, e.g., as reviewed by Keir (1995) and Crowley (1995) and simulated by Ridgwell (2001). While these could be explained by sea-level rise alone, they are not discussed here due to my limited knowledge on the subject, and will be addressed in future work.

\subsection{Pollen-based reconstruction and terrestrial modeling}

Compared to the constraint from marine ${ }^{13} \mathrm{C}$, pollen based paleoecological evidence suggests even less glacial land carbon storage (by 700-1500 Gt excluding some extreme values; Adams et al., 1990; Crowley, 1995; See Table 1 of Zeng, 2003 , for a summary of marine $\delta^{13} \mathrm{C}$, pollen and terrestrial carbon modeling results) that has been difficult to reconcile with the $500 \mathrm{Gt}$ inferred from marine $\delta^{13} \mathrm{C}$ (Crowley, 1995; Adams, 2002, unpublished note, available from J. Adams or this author). Terrestrial carbon models (forced by reconstructed climate) generally simulate smaller changes but tend to be in the same direction of the pollen and marine inferences. Then how is it possible that the result of Zeng (2003) be consistent with these results of large changes in the other direction? I argue that there are enough uncertainties in these estimates to allow the possibility of a land helper. The main reasons are:

1. Paleoecological reconstructions and other glacial terrestrial models did not include carbon stored under ice (i.e., they assume bare rock/soil after icesheet retreat). Zeng (2003) estimated this to be about $500 \mathrm{Gt}$. The likelihood of this scenario is discussed in Sect. 2.3. 
2. After icesheet retreat, re-establishment of the carbon pool is a slow process. While vegetation growth takes only decades to few hundred years, soil development can take thousands of years or longer, as evidenced by the large area of bare rock or shallow soil in the presentday Canadian Shield and Scandinavia, 10000 years after last deglaciation. Another potentially important factor is soil nutrient buildup which can also take thousands of years as suggested by studies of vegetation and soil development on a volcanic lava sequence in Hawaii spanning 4 million years (Vitousek, 2004). Because most of the carbon in cold climate is stored in soil, not vegetation, even if vegetation grows quickly on glacial tills, it will take a long time before most of this carbon pool re-establishes itself. No delay was assumed in previous terrestrial modeling studies, with the exception of Kaplan et al. (2002) who however only considered the delay of vegetation growth, not soil.

The release of glacial burial carbon would be partly compensated for by regrowth uptake on the deglaciated land. Their relative timing would play an important role in the net contribution to deglacial atmospheric $\mathrm{CO}_{2}$. Zeng (2003) assumed in-situ burial and release of glacial burial carbon, and a somewhat arbitrarily chosen timescale of a few thousand years for soil development. The model showed that despite of the release of $500 \mathrm{Gt}$ glacial burial carbon, the regions previously covered by icesheets had only a net release of about $150 \mathrm{Gt}$ after the compensation from regrowth uptake (see his Fig. 7). The magnitude of this net release depends on the relative timing of burial carbon decomposition and regrowth. This "in-situ" assumption will be relaxed in the current work by including subglaical transport.

3. The impact on carbon storage of a different glacial climate may not be fully reflected in pollen data. For instance, since pollen record is an indicator of aboveground vegetation, a 'modern analog' approach needs to be used to infer soil carbon. The much colder glacial climate at higher latitude may lead to slower decomposition, thus higher soil carbon storage which may have been underestimated by the pollen reconstructions.

At first sight, these arguments are in apparent contrast with a typical depiction of a "drier and colder" glacial climate that is not conducive to vegetation growth. This picture standing alone may be correct, but I argue that it would be overly simplistic if one then infers that this necessarily means less carbon storage, as implied in many studies. My reasoning is as following.

Firstly, yes, it is true that glacial climate was much colder, with global mean by $5^{\circ} \mathrm{C}$, even more at high latitudes, as indicated by both paleo data and modeling, and yes, extremely low temperature such as in present day high arctic region is the most important limiting factor for vegetation so that all the growth takes place in the short summer growing season by the tundra grass. However, despite of the small quantity of above-ground vegetation biomass, tundra soil has one of the highest carbon density among the world's major ecosystem types. This is precisely because of the low activities of decomposers at low temperature, with the decomposition rate exponentially dependent on temperature. This temperature dependence is often represented by a so-called Q10 value of about 2 (decomposition rate doubles with every $10^{\circ} \mathrm{C}$ temperature increase) at $25^{\circ} \mathrm{C}$, and even higher at lower temperature (e.g., Kirschbaum, 1995).

Precipitation was generally reduced during glacial times, but model simulations show significant difference in magnitude and spatial pattern (Kageyama et al., 2001). The overall impact of this uncertainty may be smaller than many other factors. One important compensation for reduced precipitation is that the much colder temperature reduces evaporation, thus retains more soil moisture which is what matters directly to vegetation growth (Zeng et al., 2005). This is largely responsible for the wet soil at high latitudes despite of the lower precipitation compared to tropical and midlatitude regions.

Thus, the not so dry but much colder glacial climate can allow more carbon to accumulate in soil regardless of the uncertainty in above-ground biomass or vegetation type changes. Indeed, there is emerging evidence from studies in Siberia that the periglacial environment during LGM was more productive and carbon-rich than previously thought (Zimov et al., 2006).

Another major uncertainty concerns the dependence of plant productivity on atmospheric $\mathrm{CO}_{2}$ level, i.e., the " $\mathrm{CO}_{2}$ fertilization" effect. Lowered $\mathrm{CO}_{2}$ level at glacial times means lower productivity. Traditionally, models used parameterizations for $\mathrm{CO}_{2}$ fertilization that were strong enough to explain the modern "missing $\mathrm{CO}_{2}$ problem" (e.g., Sarmiento and Gruber, 2002). However, recent evidence attributes much of the missing $\mathrm{CO}_{2}$ to other factors such as forest regrowth (Pacala et al., 2001; Caspersen et al., 2000), though the strength of $\mathrm{CO}_{2}$ fertilization is still highly uncertain, to a larger extent related to the multiple limitations imposed at ecosystem level and longer timescales (Field, 2000; Luo et al., 2006).

The impact of this uncertainty on terrestrial carbon model can be large. For instance, the $800 \mathrm{Gt}$ increase from glacial to interglacial simulated by the model LPJ (Kaplan et al., 2002) was reduced to about $200 \mathrm{Gt}$ when $\mathrm{CO}_{2}$ fertilization was kept at constant. Similar sensitivity was seen in the CARAIB model (Otto et al., 2002) with $\mathrm{CO}_{2}$ fertilization almost solely responsible for the deglacial biospheric expansion. In comparison, the dynamic vegetation and carbon model VEGAS used by Zeng (2003) has a weaker dependence on $\mathrm{CO}_{2}$ due to multiple limitations (Zeng et al., 2004; Friedlingstein et al., 2006), and its effect was largely compensated for by the temperature effect on soil carbon in his glacial simulation.

In summary, the compensating effects of the three main climate factors (temperature, $\mathrm{CO}_{2}$, precipitation) are such 
that outside the area covered by icesheets at glacial maximum, overall terrestrial carbon pool change is moderate. The total land-atmosphere carbon transfer is a combination of contribution from non-ice/non-shelf areas, continental shelves, ice covered area (see his Fig. 7 for the numbers from that model simulation), with the latter in turn depending on a partial cancellation between the decomposition of burial carbon and regrowth.

\subsection{Freezer or bulldozer?}

The key assumption of the glacial burial hypothesis is that the vegetation and soil carbon accumulated during an interglacial was buried during glaciation, followed by preservation and later release at deglaciation. An alternative fate of this carbon pool is that it was destroyed as icesheets advanced, with $\mathrm{CO}_{2}$ released back into the atmosphere. One may visualize the glacial burial hypothesis as the "freezer" hypothesis, and the alternative the "bulldozer" hypothesis. Zeng (2003) made the explicit freezer assumption, while other terrestrial carbon models made the bulldozer assumption, either explicitly when continuous simulation over glacial-interglacial cycles demanded the accounting of this carbon pool (Koehler et al., 2006), or implicitly in most other modeling by assuming no carbon under icesheet in time slice simulations.

The view of an icesheet acting like a bulldozer stems from the observation of mountain glaciers. These ice masses sweep down whatever is on their way, carry them together with fallen debris and sediments scraped off the bottom or mountain side, and then dump them in the ablation zone or leave them behind as glacial moraines when they retreat. Because their movement is sufficiently slow, most fallen vegetation would have enough time to decompose and release carbon into the atmosphere. Some carbon could still be preserved in this case if they are protected by sediment soil and ice, or simply decompose very slowly in the cold and dry periglacial environment. Indeed, it is not uncommon to find old tree trunks or even animals preserved from the Little Ice Age in periglacial environment of mountain glaciers in the Alps and the Rockies, but overall the quantity of carbon preserved this way would be quite small.

However, when continental-scale glaciation is considered, I argue for a drastically different picture. At glacial inception when climate becomes progressively colder, summer becomes colder and shorter. At the point when summer heating is not enough to melt away snow accumulated during the cold seasons, vegetation and soil would be covered by a perennial blanket of snow that would accumulate as climate cools further. Obviously, there is ample time before this threshold is reached for vegetation to change, e.g., from Boreal forest to tundra. Such vegetation and soil dynamics needs to be taken into account and it was modeled in Zeng (2003) and this work. It is important to note that such ecosystem succession does not necessarily imply that only a small quantity of carbon is available for burial, because tundra can contain large amount of soil carbon (Sect. 2.2). There would also be a period immediately after permanent snow cover but before ice enclosure when dead carbon could be decomposed and released, but the bacterial activity should be sufficiently slow to allow the preservation of a large part of the snow-covered carbon.

There has long been the debate on glaciation's "highland origin" (Flint, 1943) vs. "in situ" formation (Yves, 1962), relevant respectively to the "bulldozer" and "freezer" hypotheses discussed above. Although glaciers formed in the mountains such as the Cordilleran or high arctic mountains could flow downhill and cover some surrounding lowland, the area extent would be limited. It is hard to imagine that such glaciers could flow thousands of kilometers across the Canadian Plain. Most of the continental-scale glacial inception must have been largely in situ. Our understanding of such processes is robust enough now so that dynamic icesheet models nearly always produce glacial inception as the result of in situ snow accumulation (e.g., Vettoretti and Peltier, 2004).

Even in the case of a large icesheet or icecap moving laterally towards warmer region so that the land is significantly disturbed before covered by ice (rather than blanketed by snow), there is still good probability for large organic carbon preservation. This is because the cold periglacial environment could contain significant amount of carbon in, e.g., the form of tundra soil or peat, that would decompose very slowly even if covered by flowing ice, as long as it was not scraped off.

Nevertheless, when icesheet becomes large enough, subglacial movement will become significant especially when basal melting occurs. This may lead to ejection of glacial burial carbon that will be the focus of this paper. Icesheets also advanced and retreated on sub- 100 ky cycles, and this would destroy some carbon, especially at the edge of an icesheet. However, vegetation would grow back where icesheets had retreated, and became covered again when ice came back. If such oscillations were faster than vegetation and soil reestablishment, little carbon would be there for reburial. Faster oscillations (decades to centuries or millennia) generally corresponds to icesheet changes on much smaller area so this effect should not have a major impact on the overall carbon change on $100 \mathrm{ky}$ timescale. Over the 20 and $41 \mathrm{ky}$ cycles that dominate the sub-100 ky spectrum, vegetation and soil would have enough time to reestablish during these cycles, albeit these carbon would be younger than the carbon buried in the central regions of the icesheet that do not melt during these cycles.

Is there any direct physical evidence of extremely ancient carbon preserved by ice, older than mammoths frozen in Siberia permafrost or ice man in the Alps? The answer is yes, with a few examples below. 
- Exposed shrub near an retreating Andean mountain glacier was dated over 50000 years old (Thompson, 2004).

- In Greenland, the last section of an ice core is brown-silt colored, with $\mathrm{CO}_{2}$ (130 000 ppmv) and $\mathrm{CH} 4$ (6000 ppmv) concentration orders of magnitude higher than in the atmosphere (Souchez, 1997), indicative of decomposed ancient organic matter.

- At the bottom of a Greenland ice core, a piece of organic matter was suspected to be a needleleaf or a grass blade. Since it was at the bottom of an icesheet dome, its age is probably over 2 million years.

- Organic sediments dated from the Eemian interglacial (approximately $120 \mathrm{ky}$ ago) by biostratigraphy in the glacial deposits of Scandinavia suggest that they may have been preserved until the final deglaciation (Forsstrom and Punkari, 1997; Punkari and Forsstrom, 1995). Similar interpretation could be said to organic deposits from Hudson Bay lowland that was once the central part of the Laurentide icesheet (Dredge et al., 1990).

Obviously, these findings can not be taken as proof of a continental-scale carbon burial by ice, but they suggest the possibility of preserving carbon for long period of time by ice under a variety of conditions. Among them, the last type may be most relevant to the glacial burial hypothesis here. Since the strongest evidence would come from undisturbed ice-buried carbon from previous interglacials, I speculate that high arctic islands such as Ellesmere, Baffin, and Axel Heiberg in Canada would be good places to look for carbon from last interglacial. Since the Eemian was about $0.5-1{ }^{\circ} \mathrm{C}$ warmer than the Holocene, these islands would have more exposed land for vegetation growth at that interglacial, which would have been buried during the subsequent glacial inception. Since it might have never been warmer during the last glacial-interglacial cycle, the Eemian carbon on these islands is perhaps just being exposed to the atmosphere as the ice caps retreat due to the current warming (ironically and likely due to anthropogenic $\mathrm{CO}_{2}$ emission).

Indeed, based on ecological and microbiological studies in these regions and Greenland, Welker et al. (2000) and Skidmore et al. (2000) speculated that the regrowth of tundra vegetation in the newly exposed land and microbial activities under ice are 'feeding' on ancient carbon and nutrient, although there has been no direct identification or dating. However, if significant disturbance occurred in these ice caps such as over the sub-100 ky cycles, or during warmer than Eemian but brief (so not seen in the low resolution paleo temperature record) periods, clean evidence of ice-buried Eemian carbon will be more difficult to obtain.

\subsection{How can we make progress}

In his conclusion, Zeng (2003) suggested four key steps for advancing our understanding of the glacial $\mathrm{CO}_{2}$ problem should the terrestrial biosphere be a helper: (1) search of direct evidence of glacial burial carbon under the former ice sheets such as the Laurentide, by discovering and analyzing the remains of a largely destroyed carbon reservoir; (2) high resolution measurement of atmospheric ${ }^{13} \mathrm{C}$ preserved in ice cores, extending back in time to cover earlier deglaciations, because it provides critical information on the relative contributions of land and ocean; (3) transient coupling to high resolution ocean models with sediment component, and incorporating other oceanic mechanisms, so as to compare with the vast array of ocean sediment data for both carbon and ${ }^{13} \mathrm{C}$; Both whole ocean or basin wide synthesis and site by site comparison are needed; (4) intercomparison and validation of terrestrial carbon models and paleoclimate reconstructions, in order to narrow down the uncertainties associated with climate forcing and model parameterizations.

Little progress has been made along these directions, except for (2) as measurements on the EPICA ice core (Leuenberger et al., 2005) clearly show a deglacial drop-rise transition in atmospheric $\delta^{13} \mathrm{C}$, in support of the earlier icecore measurements from Taylor Dome (Smith et al., 1999) and analysis of organic matter stowed away by ancient packrats in southwestern US (Marino et al., 1992). These can be explained straightforwardly by a light terrestrial carbon input (Sect. 2.1 above).

The lack of progress is a direct result of a lack of appreciation or outright rejection of the glacial burial hypothesis, mostly because it predicts that land is a "helper" in explaining the glacial $\mathrm{CO}_{2}$ problem, contrary to the marine ${ }^{13} \mathrm{C}$ inference and pollen reconstruction. In a broader context, this reflects a general "wariness" on the glacial $\mathrm{CO}_{2}$ problem, to quote from a succinct review by Crowley (2002):

"..., there is no consensus on what causes ice-age $\mathrm{CO}_{2}$ changes. The sheer number of explanations for the 100000 year cycle and for $\mathrm{CO}_{2}$ changes seem to have dulled the scientific community into a semipermanent state of wariness about accepting any particular explanation. This places a great burden of proof on proponents of any particular theory; any explanation seeking consensus acceptance must at this stage be characterized by mathematic completeness and predictability against a wide array of geological data. Most importantly, the explanation should be falsifiable - a step sometimes neglected in this and other fields."

It is my hope that the arguments I made above will be convincing enough to motivate at least a small number of experts to consider the alternative land 'helper' role in conjunction with other active oceanic mechanisms, and check the outcome against the impressive amount of data from the Quaternary. Major advancement could be made in the following area, in approximate order of ease: 

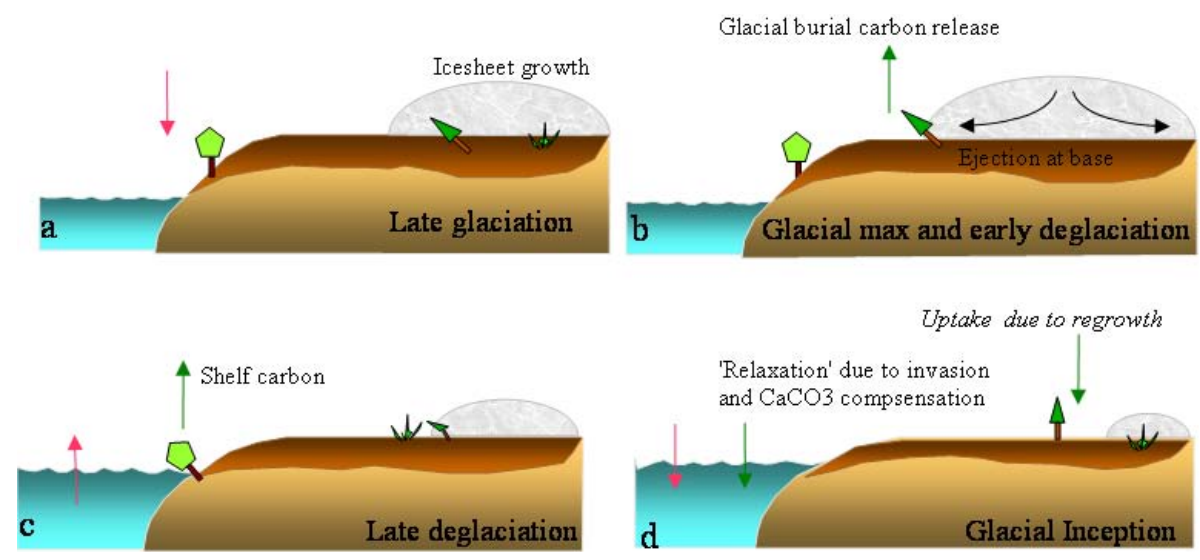

Fig. 1. Conceptual diagram of proposed carbon-climate-icesheet feedback mechanism during some major stages of the $100 \mathrm{ky}$ cycle: (a) late glaciation, cold climate enhanced by feedbacks such as $\mathrm{CO}_{2}$-temperature and ice-albedo-topography, with about $500 \mathrm{Gt}$ carbon accumulated under the icesheets; (b) glacial maximum and early deglaciation with basal ejection of glacial burial carbon and subsequent $\mathrm{CO}_{2}$ release as the trigger; (c) late deglaciation with also continental shelf carbon and oceanic $\mathrm{CO}_{2}$ release; (d) glacial inception, initiated by relaxation from rapid deglacial land $\mathrm{CO}_{2}$ release due to deep ocean invasion and $\mathrm{CaCO}_{3}$ compensation, and vegetation regrowth. Red arrows indicate fluxes due to other oceanic mechanisms such as SST change.

- A terrestrial carbon model intercomparison or a critical appraisal of published results focusing on temperature and precipitation effect on glacial land carbon storage. The state-of-the-art carbon models have reached a degree of maturity such that some degree of consensus can be expected. The outcome will also shed important light on the extent to which pollen reconstruction may be applied to the "no modern analog" situations, especially concerning temperature influence on soil decomposition.

- Direct physical evidence of organic carbon buried during the Eemian from the high Arctic islands.

- Careful examination of the newly available glacialinterglacial $\delta^{13} \mathrm{C}$ data from ice cores, together with marine $\delta^{13} \mathrm{C}$ and other data. Ice core $\delta^{13} \mathrm{C}$ are emphasized because they are measures of a well-mixed atmosphere. In comparison, $\delta^{13} \mathrm{C}$ from marine foraminiferal shell is subject to spatially heterogenous influences such as changes in thermohaline circulation, stratification, biological pump, and carbonate ion effects. A modeldata synthesis approach will be needed by coupling the state-of-the-art terrestrial and 3D ocean carbon models in which various scenarios can be tested against the full suite of paleo data. This is ambitious and requires an interdisciplinary effort in interpreting the results, but it is necessary and do-able. The outcome will help to resolve some of the key issues such as amplitude, phasing of $\mathrm{CO}_{2}$, the drop-rise transition in atmospheric and surface ocean $\delta^{13} \mathrm{C}$ at termination, and the interpretation of deep ocean $\delta^{13} \mathrm{C}$ and $\mathrm{CaCO}_{3}$ dissolution events.

In contrast, some other important assumptions will be more difficult to quantify at present, including the effect of $\mathrm{CO}_{2}$ fertilization, the details of organic carbon burial at glacial inception and their modification under icesheet, the exact amount, rate and timing of subglacial ejection of burial carbon (the focus of this paper), and regrowth uptake.

Although the burden of proof is on the proponents of the theory, the possible constraints that need to be considered are beyond the scope here. Although the glacial burial hypothesis is not yet proven, it opens the door to some new possibilities that may be of value to the unsolved $100 \mathrm{ky}$ problem. In this paper, one assumption, namely, the "in situ" burial and release made in Zeng (2003) will be relaxed, leading to an internal triggering mechanism for deglaciation.

\section{A carbon-climate-icesheet feedback mechanism}

Here I include some ingredients from the glacial burial hypothesis in a fully coupled carbon-climate-icesheet framework, rather than considering carbon cycle or climate separately with the other as forcing. An important new element is the hypothesis that the glacial burial carbon would be transported out of the icesheets when icesheet is sufficiently large, thus providing a switch mechanism to transit the system from glacial maximum to interglacial. The theory is outlined as following.

During glaciation (Fig. 1a), the cooling drives down atmospheric $\mathrm{CO}_{2}$ through carbon storage in the ocean due to several effects such as lower sea surface temperature (SST), and on land due to lower soil decomposition rate, as well as vegetation growth on exposed continental shelves. The lower $\mathrm{CO}_{2}$ would further reduce temperature through weaker greenhouse effect. While oceanic $\mathrm{CO}_{2}$ change is also influenced by many other factors such as plankton productivity, 
the land and ocean changes described above consist a wellknown $\mathrm{CO}_{2}$-temperature feedback. A main addition here from the glacial burial hypothesis is that during glaciation, part of the vegetation and soil carbon accumulated around the preceding interglacial was buried and preserved under the major Northern Hemisphere icesheets.

When an icesheet grows long enough and reach certain size, the buried carbon is transported out of the icesheet at the edge (Fig. 1b). This dead carbon may have been significantly transformed, but would nonetheless be released back into the atmosphere. If the release of this carbon is fast enough to outcompete the oceanic buffering effects, $\mathrm{CO}_{2}$ would accumulate in the atmosphere and would lead to rising $\mathrm{CO}_{2}$, which would warm the atmosphere and melt icesheets, and this would lead to further release of glacial burial carbon as well as continental shelf carbon (Fig. 1c). With the help of $\mathrm{CO}_{2}$-temperature and ice-albedo feedbacks, the system could get into a runaway deglaciation.

The deglaciation ends at interglacial when the major icesheets are melted away and the major "independent" carbon sources, namely glacial burial and continental shelf carbon are finished. If the deglacial land $\mathrm{CO}_{2}$ release is faster than or comparable to the oceanic buffering timescales, in particular, the deep ocean invasion timescale of $1 \mathrm{ky}$ and the $\mathrm{CaCO}_{3}$ compensation timescale of $10 \mathrm{ky}$ (Archer et al., 1997; Sigman and Boyle, 2000; Zeng, 2003), the interglacial would only be transient as atmospheric $\mathrm{CO}_{2}$ would relax back towards an equilibrium value, analogous to the ocean uptake of the anthropogenic $\mathrm{CO}_{2}$ pulse. In the meantime, regrowth in the Boreal region after icesheets retreat would also take $\mathrm{CO}_{2}$ out of the atmosphere. With the help of various positive feedbacks, this $\mathrm{CO}_{2}$ drawdown could drive the system into a glacial inception (Fig. 1d), followed by further glaciation, thus completing one cycle.

\section{Modeling approach}

An Earth system model with balanced complexity in the components has been used to quantify the above theory. The physical climate components we use are "semi-empirical" by interpolating GCM-simulated time slices (Kutzbach et al., 1998) and reconstructed icesheet distributions for the last $21 \mathrm{ky}$ (Peltier, 1994). The interpolation weighting factor is determined by time-dependent $\mathrm{CO}_{2}$, ice cover and topography. The carbon cycle models for both land and ocean are mechanistic. The details of the model components are provided in the appendix while the following summarizes the main aspects.

In the "semi-empirical" atmosphere model, precipitation and temperature simulated by CCM1 (Kutzbach et al., 1998) for the Holocene $(6 \mathrm{kBP})$ are used as the model's interglacial maximum $(\mathrm{Im})$, while its LGM (21 ky BP) simulation is used as glacial maximum $(\mathrm{Gm})$. Thus the physical atmosphere is represented by a single time-dependent variable $w(t)$ in addi- tion to the spatial distributions at $\mathrm{Gm}$ and $\mathrm{Im}$. For instance, temperature $T(x, t)$ can be computed as a linear interpolation between the two spatially varying extreme states $T_{I m}(x)$ and $T_{G m}(x)$ simulated by CCM1, with $w$ as the weighting factor:

$T=w T_{I m}+(1-w) T_{G m}$

where $t$ is time and $x$ represents the spatial dimensions, and $w=w(t)$ is a function of time only.

The climate factor $w$ is determined by three independent factors as:

$w=0.5 w_{c}+0.3\left(1-w_{i}\right)+0.2\left(1-w_{h}\right)$

where $w_{c}$ is the contribution from the greenhouse effect of atmosphere $\mathrm{CO}_{2}, w_{i}(t)$ is due to ice-albedo feedback of the icesheets, and $w_{h}(t)$ is related to atmospheric circulation changes caused by the topographical height of the icesheets. The relative importance of these three factors were chosen to be $50 \%, 30 \%$, and $20 \%$, based on estimates of the relative roles of greenhouse gases and icesheets (Broccoli and Manabe, 1987; Lorius et al., 1990; Weaver et al., 1998).

Ice cover change $w_{i}$ is assumed to follow temperature change. The ice distribution information is based on the paleo ice cover and topography data of Peltier (1994) at $1 \mathrm{ky}$ time resolution. However, unlike the straightforward interpolation for temperature and precipitation which can also be extrapolated, ice cover is either 0 or 1 . Ice cover "interpolation" is therefore done by spreading (glaciation) or shrinking (deglaciation) the ice cover based on the information of $w_{i}$. Ice volume grows towards a potential value determined by the LGM data of Peltier (1994) and current ice cover $w_{i}$.

For the ocean, factors such as seaice, ocean circulation are fast changing and are treated as part of the physical atmosphere-ocean-land climate system which responds to greenhouse gas and icesheet forcing. Since we are concerned about the interaction between carbon cycle and climate, we only need to represent the effects of changes in the physical climate system on the carbon cycle. A sea surface temperature (SST) anomaly is slaved to the atmosphere with a time delay of 100 year. Since it is not the purpose here to include all the active ocean mechanisms, a change of ocean temperature by $6 \mathrm{~K}$ at $\mathrm{Gm}$ was used as a surrogate of all the mechanisms. A major caveat is that this approach will not resolve significant timing differences of different ocean $\mathrm{CO}_{2}$ mechanisms, which is beyond the scope of this work. Sensitivity experiment showed that this $6 \mathrm{~K} \mathrm{SST}$ effect alone produces about 55 ppmv glacial-interglacial $\mathrm{CO}_{2}$ change, a value on the low side of which the major oceanic mechanisms can explain. This SST anomaly, along with the land-atmospheric carbon flux from the terrestrial carbon model VEGAS are given to the oceanic carbon model SUE (Ridgwell, 2001). SUE also computes atmosphere-ocean carbon exchange and atmospheric $\mathrm{CO}_{2}$ which is then used by the physical atmosphere and land photosynthesis module. 


\section{Results}

The fully coupled carbon-climate-icesheet model was first run for $10 \mathrm{ky}$ at an interglacial equilibrium, and it produced an equilibrium $\mathrm{CO}_{2}$ level of $272 \mathrm{ppmv}$ (Fig. 2). $\mathrm{CO}_{2}$ was then artificially taken out of the atmosphere at a rate of $0.015 \mathrm{Gt} \mathrm{y}^{-1}$ for the next $26 \mathrm{ky}$, corresponding to a cumulative $390 \mathrm{Gt}$ carbon sink. The system was then left to run by itself without any external forcing.

This $\mathrm{CO}_{2}$ sink was enough to bring the system into a glaciation which continued due to the positive feedbacks in the system. A glacial maximum was reached, followed by several deglaciation and glaciation cycles before the simulation stopped after 500 kys. After the first two cycles in which the model had to adjust from the artificial $\mathrm{CO}_{2}$ sink, the system settled into quasi-steady glacial-interglacial cycles with a period of $93 \mathrm{ky}$. The details over one cycle are shown in Fig. 3 and the mechanisms for the self-sustaining cycles are discussed below.

From interglacial to early glaciation, vegetation regrowth in the Boreal region leads to accumulation of vegetation and soil carbon which is later buried under ice. While regrowth contributes to most of the early land carbon increase, carbon accumulation on exposed continental shelves dominates during late glaciation. At glacial maximum, land carbon storage reaches highest value at about $2000 \mathrm{Gt}$.

Glacial maximum in the model is determined as ice volume reaches the maximum value. At this point, in addition to a normally slow height gradient dependent basal flow, the tall icesheets which are likely half melting at the base would produce significantly accelerated subglacial sediment transport through processes such as subglacial river runoff and fast flowing ice streams. Given the many unknowns on these processes, the model simply adds an additional transport to the burial organic carbon towards the edge of the icesheets at a speed increasing from zero to $250 \mathrm{~m} \mathrm{y}^{-1}$ within 3000 years.

A turning point was reached a few tens of years after the initial ejection of carbon out of the icesheets, when the decomposed burial carbon accumulates in the atmosphere enough to reverse the $\mathrm{CO}_{2}$ decreasing trend. Once $\mathrm{CO}_{2}$ starts to increase, climate warms, and several positive feedbacks act to further increase $\mathrm{CO}_{2}$, including increasing SST and warming-induced release of active land carbon. In the model, the rise of temperature lags $\mathrm{CO}_{2}$ by 80 years, which in turn responds to the initial subglacial carbon release with a delay (Fig. 4). Obviously, the quantitative details will depend on the relatively simple assumptions made in the model. Also importantly, the $\mathrm{CO}_{2}$ increase in the initial few decades (Fig. 4) is on the order of $0.1 \mathrm{ppmv}$, much lower than even the modern interannual variability of $2-3$ ppmv (Zeng et al., 2005). Thus the actual $\mathrm{CO}_{2}$ increase needs to be above certain glacial noise level before it can drive the system into a runaway deglaciation, and any significant deglaciation can only be seen on a timescale much longer than shown in Fig. 4 after initial burial carbon release. This $\mathrm{CO}_{2}$ lead is for the ini-

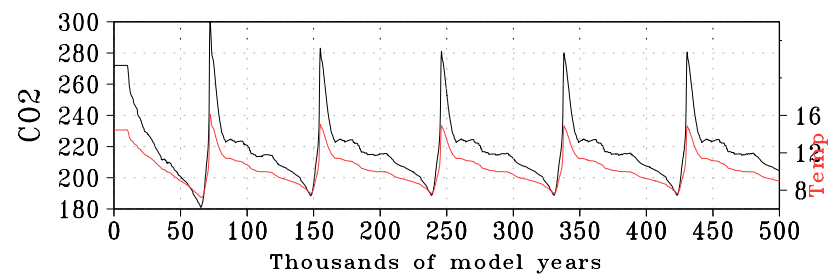

Fig. 2. Quasi-100 ky cycles simulated by the coupled model. The first two cycles are in adjustment with the model spinup and an artificial $\mathrm{CO}_{2}$ sink, followed by quasi-steady cycles with a period of $93 \mathrm{ky}$. The glacial to interglacial amplitudes are $90 \mathrm{ppmv}$ in $\mathrm{CO}_{2}$, and $6^{\circ} \mathrm{C}$ in global mean temperature.

tial triggering, and the phase relationship may change in later stages.

The model simulates two major periods of increasing $\mathrm{CO}_{2}$ during deglaciation: an early (and continuing) increase in response to the release of glacial burial carbon, and a later period when continental shelves lose carbon as sea level rises. These can be seen clearly in the two deglacial peaks in the land-atmosphere carbon flux (Fig. 3c and Fig. 5). The deglacial increase in $\mathrm{CO}_{2}$ is about 90 ppmv, while temperature increase is $6^{\circ} \mathrm{C}$ and deglaciation lasts about $7 \mathrm{ky}$.

The relative contribution to deglacial atmospheric $\mathrm{CO}_{2}$ change is about 55 ppmv from ocean, and 45 ppmv from land, as indicated by two sensitivity experiments (Fig. 5). These add to $100 \mathrm{ppmv}, 10 \mathrm{ppmv}$ larger than the $90 \mathrm{ppmv}$ change in the fully coupled run, because the ocean buffering effect is less effective at higher $\mathrm{CO}_{2}$ in the land only experiment. Thus land contribution is close to $35 \mathrm{ppmv}$ (inferred as a residual), somewhat larger than the $30 \mathrm{ppmv}$ found in Zeng (2003) where burial carbon was released in situ, thus slower than basal flow induced land carbon release here.

Interglacial maximum with highest $\mathrm{CO}_{2}$ and temperature is brief, followed immediately by $\mathrm{CO}_{2}$ drawdown and cooling over the next $10 \mathrm{ky}$. The initial $\mathrm{CO}_{2}$ decrease is rapid, mostly caused by a relaxation from the fast deglacial $\mathrm{CO}_{2}$ increase as land-originated $\mathrm{CO}_{2}$ invades into deep ocean and by $\mathrm{CaCO}_{3}$ compensation which have timescales of $1 \mathrm{ky}$ and $10 \mathrm{ky}$, respectively. This interpretation is strengthened by a $\mathrm{CO}_{2}$ drawdown of about $10 \mathrm{ppmv}$ at early glacial inception even in the "positive land" flux only case (Fig. 5), despite the lack of any $\mathrm{CO}_{2}$ uptake by land and active ocean mechanisms. It is seen clearly in the yellow line of Fig. 5 the initial drop of $10 \mathrm{ppmv}$ for $1 \mathrm{ky}$ and another $10 \mathrm{ppmv}$ decrease for the subsequent $10 \mathrm{ky}$. The amplitude of this relaxation also depends on how fast land carbon is released during deglaciation. Regrowth on land contributes a significant part of the subsequent decrease in $\mathrm{CO}_{2}$ and temperature, but not the initial 10 ppmv drop as land is still releasing $\mathrm{CO}_{2}$ at this time (Fig. 5).

The rapid $\mathrm{CO}_{2}$ decrease levels off as deep ocean invasion, $\mathrm{CaCO}_{3}$ dissolution and Boreal vegetation regrowth 

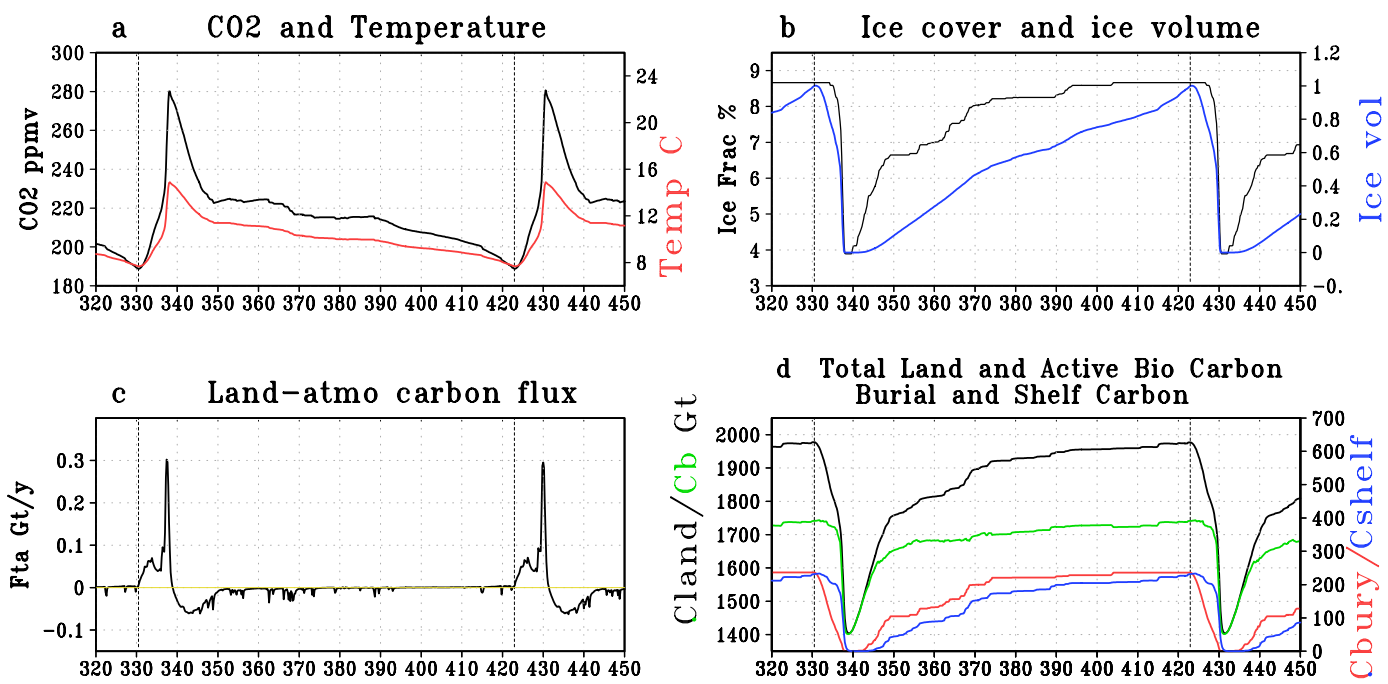

Thousands of model years

Fig. 3. Various model simulated global total or average quantities: (a) Atmospheric $\mathrm{CO}_{2}$ (black) and temperature (red); (b) Ice covered area as percentage of world total (black), and ice volume (blue) normalized between 0 (Holocene) and 1 (LGM); (c) Land-atmospheric carbon flux $\left(\mathrm{F}_{t a}\right)$; note the double peaks at deglaciation due to glacial burial carbon and continental shelf carbon release; (d) Carbon pools for total land $\left(\mathrm{C}_{\text {land }}\right.$, black $)$, active biosphere $\left(\mathrm{C}_{b}\right.$, green), glacial burial $\left(\mathrm{C}_{\text {bury }}\right.$, red $)$ and continental shelves $\left(\mathrm{C}_{\text {shelf }}\right.$, blue $)$. Vertical lines indicate the start of glacial burial carbon release.

slow down after about $10 \mathrm{ky}$. Nonetheless, this is enough to produce a significant cooling and glaciation so that ice cover is at about $50 \%$ of its maximum extent, although the icesheets are only starting to grow in height, as indicated by ice volume (Fig. 3b), consistent with results from dynamic icesheet modeling (Marshall and Clark, 2002). As a result, icesheet growth alone is able to drive further cooling despite of the flatness in $\mathrm{CO}_{2}$ over the next $15 \mathrm{ky}$. Interestingly, this continuing decrease in temperature at a time when $\mathrm{CO}_{2}$ change slows down is also seen in the ice core data (Petit et al., 1999), and it is the period when $\mathrm{CO}_{2}$ and temperature are least correlated both in the model and observations. However, such interpretation is cautioned because the detailed features may be sensitive to assumptions made in the model, and the observed features are also influenced by orbital forcing not considered here.

The last part of the glaciation again accelerates, although at a less rapid rate than glacial inception. During this period, land carbon continues to increase but at slower and slower rate because Boreal regrowth has stopped. This increase comes partly from continental shelf and partly from overall cooling-induced soil carbon storage (Fig. 3d). When icesheet grows to maximum height, glacial burial carbon is ejected and start the deglacial positive feedbacks again, followed by another quasi-100 ky cycle.

It is worth emphasizing that oceanic $\mathrm{CO}_{2}$ mechanisms, as represented by changes in SST in the model is always at work. Although the discussion above focuses on the major driving processes and key turning points in the model, the feedbacks between climate and carbon cycle on land and ocean, as well as the feedbacks between icesheets and climate all play important roles throughout a glacial-interglacial cycle.

\section{Discussion}

\subsection{Triggering mechanisms}

A key switch mechanism in the present theory from glacial to interglacial condition is the subglacial transport of glacial burial carbon. Besides large-scale ice flow, several mechanisms could act to flush out organic carbon buried under the icesheets at the height of a glacial maximum. One such mechanism is through streams of meltwater at the base of an icesheet, as evidenced by eskers left behind by the great Northern Hemisphere icesheets. Indeed, more than half of the Laurentide and Fennoscandian periglacial sediment has been deposited by meltwater. It is possible that the basal melting at a glacial maximum before and during deglaciation also carried significant amount of organic carbon which may have left evidence in such as Mississippi river sediments in the Gulf of Mexico. Another mechanism involves fast flowing ice streams (MacAyeal, 1993) which could be very efficient at transporting and exposing large amount of carbon already near the edge of an icesheet. Some other processes such as iceshelf calving may also have played a role. However, these processes are poorly understood, and geological and modeling evidence show frozen bed under 
the ice domes and melting at outer areas at the last glacial maximum (LGM), followed by rapid inward melting during deglaciation (Kleman and Hattestrand, 1999; Marshall and Clark, 2002). In the absence of better understanding and availability of modeling tools, an extremely simple treatment has been used here, with the caveat that it may not capture the details accurately of deglacial burial carbon release and the differences from termination to termination.

In this theory, a synchronous initial ejection of the buried carbon on a global scale is not required to trigger a deglaciation. Because of the different size and growth history of the icesheets, the larger ones, most likely the Laurentide Icesheet would have ejected subglacial carbon first, thus initiating the deglaciation. The release of carbon under smaller icesheets would follow somewhat later as temperature increased. Even under the Laurentide icesheet, most of the burial carbon, especially that under the central frozen bed, would have been released throughout the deglaciation as part of the climatecarbon feedback.

So far I have focused on the $100 \mathrm{ky}$ cycle. The decay of icesheets over the $20 \mathrm{ky}$ and $41 \mathrm{ky}$ cycles may destroy some glacial burial carbon, but regrowth of the icesheets would bury them in a way similar to the major glacial inceptions on 100 ky timescale. Perhaps more importantly, such process is more likely to occur near the southern edge of the icesheets, thus impacting only a relatively small carbon pool. In contrast, basal transport is likely much more significant near glacial maximum than during the minor glacial periods because the slow icesheet growth.

Interestingly, apart from the switch mechanisms at glacial maximum and interglacial, most of the major processes are the same during glaciation and deglaciation, such as $\mathrm{CO}_{2}$-temperature and ice-albedo feedbacks, carbon storage/release on continental shelves, Boreal carbon burial by ice and regrowth. A major difference is the different timescales as deglaciation lasts less than $10 \mathrm{ky}$ while glaciation is an order of magnitude longer. This is mostly due to the asymmetry in icesheet melting and growth because melting is driven by radiative forcing while growth is limited by snow precipitation rate. This fundamentally explains the "sawtooth" structure of the observed $100 \mathrm{ky}$ cycles. This icesheet growth/decay asymmetry has long been noted (Oerlemans, 1980), and the new insight here is its direct interaction with the carbon cycle.

Another noteworthy feature is the transient nature of interglacials. Vegetation regrowth, especially the relaxation due to deep ocean invasion and carbonate compensation are on timescales from $1 \mathrm{ky}$ to $10 \mathrm{ky}$, so interglacials are short, at least the part controlled by $\mathrm{CO}_{2}$. In contrast, although there is no true equilibrium glacial maximum, the fact that icesheet growth is slow especially at large height when precipitation is minimum leads to significantly longer glacial maximum. The relaxation and regrowth provide the switch from interglacial to glaciation. The relatively fast timescale of this switch is fundamental to the transient nature of $\mathrm{CO}_{2}$ maximum, even if astronomical forcing happens to maintain high temperature. Such mechanisms may account for a ubiquitous initial $\mathrm{CO}_{2}$ drop in the beginning of interglacials, but the widelyvarying duration of the observed interglacials will also need orbital forcing to explain.

Interestingly, a recent work by Weitemeyer and Buffett (2006) explicitly assumed organic carbon burial under the Laurentide icesheet as a source of methane generation. It is also worthwhile to note the "peatland hypothesis", independently proposed by Klinger (1991) and Franzen (1994), with further development in Klinger et al. (1996) and Franzen et al. (1996). In this hypothesis, carbon accumulated in peatlands during an interglacial such as the Holocene (global peatland carbon is estimated at $300-500 \mathrm{Gt}$ ) would draw down atmospheric $\mathrm{CO}_{2}$, thus initiates an ice age. Both in Zeng (2003) and this work, wetland was not explicitly modeled, so that the inclusion of this additional carbon would further increase the magnitude of land carbon contribution, although not by as much as 300-500 Gt because the current model already contains large amount of carbon in the form of tundra soil in the present-day peatland regions. Perhaps more importantly, since current peatland was accumulated during the Holocene (Smith et al., 2004) which is a long interglacial, the role of peat formation may be less important during shorter interglacials such as the Holsteinian. The current work focuses on the mechanisms that are applicable over an "average" glacial-interglacial cycle, and wetland will be considered in future research including astronomical forcing in which the differences among different interglacials can be distinguished.

The two key switch factors for the simulated glacialinterglacial cycles, namely, the deglacial trigger of subglacial burial carbon transport and glacial initiation by $\mathrm{CO}_{2}$ relaxation from an interglacial high value and vegetation/soil regrowth, are both difficult to prove either 'right or wrong', not in the sense that they do not play a role, but whether they are strong enough to drive the climate-carbon system into a deglaciation or glaciation. This difficulty is fundamentally because of our lack of understanding and observational constraints on the relevant processes such as subglacial sediment transport and vegetation/soil development, and the complex interaction with external forcings. This is probably also why such ideas had not been seriously considered in the past.

One way of making progress is to use model experiments to study its sensitivities and then assess the realism of assumptions and parameter values that are responsible for the simulated features. The sensitivity experiments I have conducted so far with the present model indicates that the range of parameter values that can lead to self-sustaining quasi-100 ky cycles is small. However, it would be naive to think that this proves either way, for two important reasons: (1) external forcings were not considered; (2) processes responsible for the switch mechanisms are poorly understood and represented in a less-than-satisfactory way. A fuller and fairer assessment will be possible after the inclusion of 


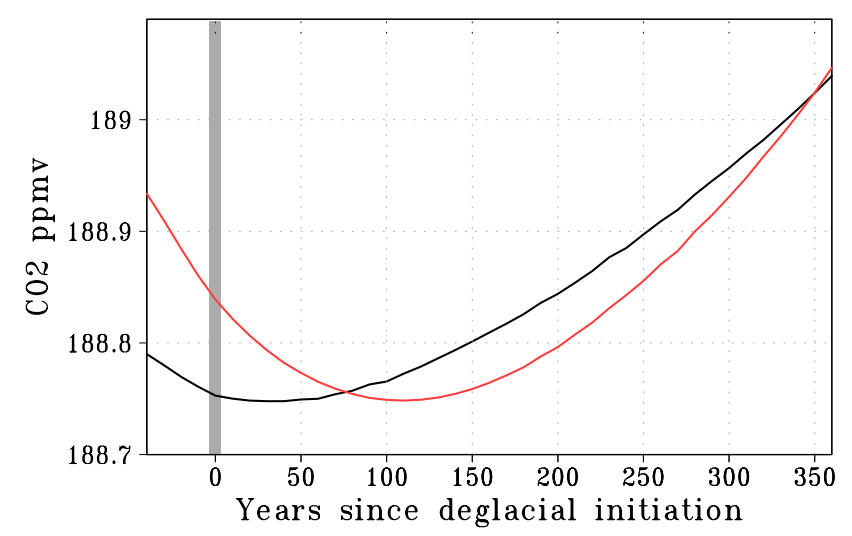

Fig. 4. Possible timing of events in a scenario in which a major icesheet grows tall and long enough so that subglacial movement starts to transport glacial burial carbon out of the icesheet (deglacial initiation, marked by gray vertical line as year 0 ). The release of burial carbon leads to atmospheric $\mathrm{CO}_{2}$ (black line) rise after 25 years, followed by temperature (red line, no label) increase after another 80 years. This plot is a zoom-in of Fig. 3 a.

astronomical forcing and further improvement of the model. Such a fuller picture will most likely emerge as one in which these mechanisms play roles more important at some phases than others, in a way complementing the role of external forcings (see an example speculation below).

\subsection{Internal feedbacks vs. external forcing}

The glacial-interglacial cycles simulated here are selfsustaining without external forcing. These quasi-100 ky cycles occur within certain plausible range of parameter values that need to be better identified perhaps in simpler models. Sensitivity experiments conducted so far indicate that they need relatively fast burial carbon release and carbon-climate feedback of sufficient strength. The key termination switch due to glacial burial carbon ejection requires only subglacial transport to become substantial. This needs a major icesheet to grow tall and long enough, without the requirement of increase in solar forcing.

This internal triggering mechanism might have played a role in the "stage-11" problem (large deglaciation at a time of low solar variability). Perhaps more importantly, it provides a potential solution for the "causality problem", i.e., observed deglaciation led solar "forcing" at Termination II, as suggested by the well-dated vein calcite in the Devil's Hole in Nevada (Winograd et al., 1992; however, see the unsettled debate, e.g., in Imbrie et al., 1993b; Crowley, 1994; Edwards et al., 1997), and high precision dating of Barbados coral reef terraces (Gallup et al., 2002). These records suggest that deglaciation started up to 10000 years before the rise in insolation at $60 \mathrm{~N}$, a standard marker of orbital forcing's impact on Northern Hemisphere icesheet dynamics (e.g., Imbrie et al., 1993a).

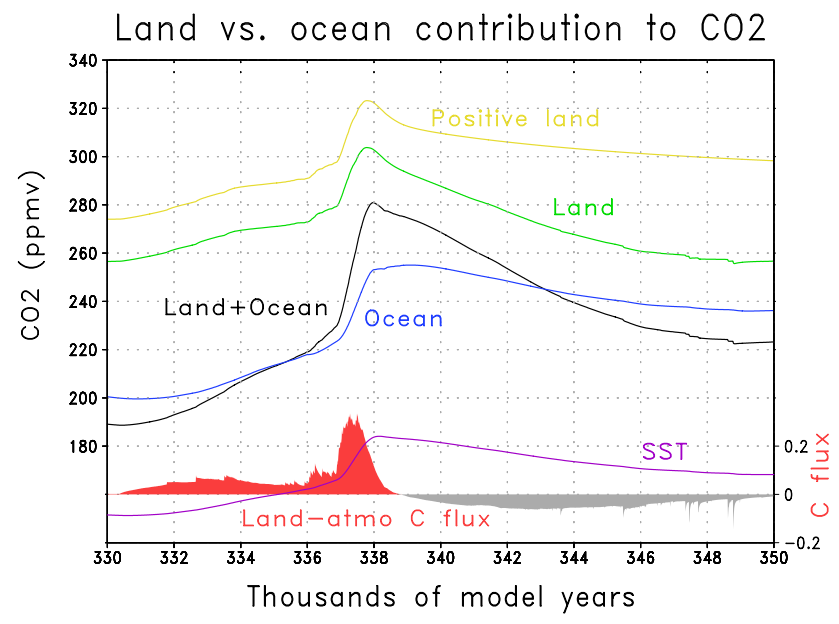

Fig. 5. $\mathrm{CO}_{2}$ change during deglaciation and glacial inception from 3 sensitivity experiments in which the atmosphere-ocean carbon model was forced by: 1 . ocean changes only (blue line; using SST cooling of $6^{\circ} \mathrm{C}$ at glacial max as a surrogate of all active ocean mechanisms, with SST in purple; this SST "piggybacking" may not resolve the timing differences in different ocean mechanisms); 2. land flux forcing only (green, with land-atmo carbon flux shown as red-gray shaded curve; note the double peaks at deglaciation due to the earlier glacial burial carbon and later continental shelf carbon release); 3. the positive part of land flux forcing only (yellow), i.e., the negative flux (shaded in gray) was set to zero. The forcing SST and land flux are from the fully coupled run (land+ocean) whose $\mathrm{CO}_{2}$ change is shown in black. The "land" only curve is shifted upward because of the lack of oceanic forcing, and the "positive land" curve is further shifted because there is no negative flux to balance the input to the atmosphere-ocean system. Note the $\mathrm{CO}_{2}$ drawdown of about 10 ppmv at early glacial inception even in the "positive land" flux only case, despite the lack of any $\mathrm{CO}_{2}$ uptake by land. This is caused by a relaxation from the high interglacial $\mathrm{CO}_{2}$ as land-originated carbon is absorbed into deep ocean by thermohaline circulation and $\mathrm{CaCO}_{3}$ compensation.

Using an ingenious dating approach with Argon isotope in the air bubbles as temperature indicator, Caillon et al. (2003) was able to circumvent the gas age-ice age uncertainty associated with deuterium temperature indicator. Their results show a $800 \pm 200$ years $\mathrm{CO}_{2}$ lag behind temperature at Termination III. At its face value, this would rule out the possibility of deglaciation being driven by $\mathrm{CO}_{2}$ increase. Here I propose a somewhat more complex scenario where some terminations were initiated by orbital forcing, and some others were initiated by $\mathrm{CO}_{2}$ increase. Termination III was likely an example of the former case (driven by orbital forcing). If looking for candidates for the latter (initiated by $\mathrm{CO}_{2}$ ), I would (boldly) predict Termination II by putting faith on the accuracy of dating and underlying assumptions of the Barbados coral reef and Devil's Hole calcite evidence. By "underlying assumptions", I mean those that link the variations in these records to Termination II, as opposed to possible regional explanations 
(Crowley, 1994; Herbert et al., 2001) for Devil's Hole, and any other potential interpretations for the sea-level data from Barbados.

Actually, there are more fundamental reasons to think that this may be the case. One reason is that if glacial burial carbon ejection was to be the trigger without coinciding orbital forcing, a long and cold period preceding the termination would be needed to grow the icesheets to the point of large basal flow or instability. A quick examination of the Vostok or EPICA data shows the glacial period before Termination II being a top candidate (the glaciation ending at LGM is arguably comparable in length but there was a much longer cold period before Termination II). In contrast, the glacial period preceding Termination III appeared to least satisfy this requirement over the last $400 \mathrm{ky}$. Obviously, such a proposal would raise more questions than it answers, and significant further research is needed before it can be considered viable. Nevertheless, from the observational side, accurate dating of the phase relationship between $\mathrm{CO}_{2}$ and temperature for Termination II using methods such as that of Caillon et al. (2003) will be most illuminating.

These two cases will also have very different characteristics beyond simple lead or lag that should help with their identification in ice core data. If $\mathrm{CO}_{2}$ drives temperature, their initial rise would appear nearly synchronous at the resolution of paleo records (Fig. 4) because the atmosphere and land-surface respond to greenhouse forcing on the order of days to months (though ocean can take up to several hundred years). In fact, this is analogous to the projected future climate change in response to fossil fuel $\mathrm{CO}_{2}$.

In contrast, if temperature drives $\mathrm{CO}_{2}$, the lag could be significantly longer, controlled largely by slow carbon processes in the deep ocean and slow soil carbon pools, though there are also faster responses in vegetation and surface ocean. However, complications will come from the phase difference or overlap of contributions from different terrestrial and oceanic mechanisms during different sub-stages of a termination.

\section{Conclusions}

Previous models that have been applied to long-term simulations tend to be simple, and it has been difficult to distinguish their relative merit (Roe and Allen, 1999; Crowley, 2002). It is my hope that the mechanisms suggested here are sufficiently specific and the predictions are falsifiable, especially after astronomical forcing is included in the future to give enough details that can be compared to observations event by event. Marine $\delta^{13} \mathrm{C}$ and carbonate data can provide major constraints on such model, but they need to be interpreted carefully together with other data such as ice core and terrestrial records in light of the transient nature of the phenomenon as well as new understanding of the glacial climate states. The modeling approach here is fairly comprehensive

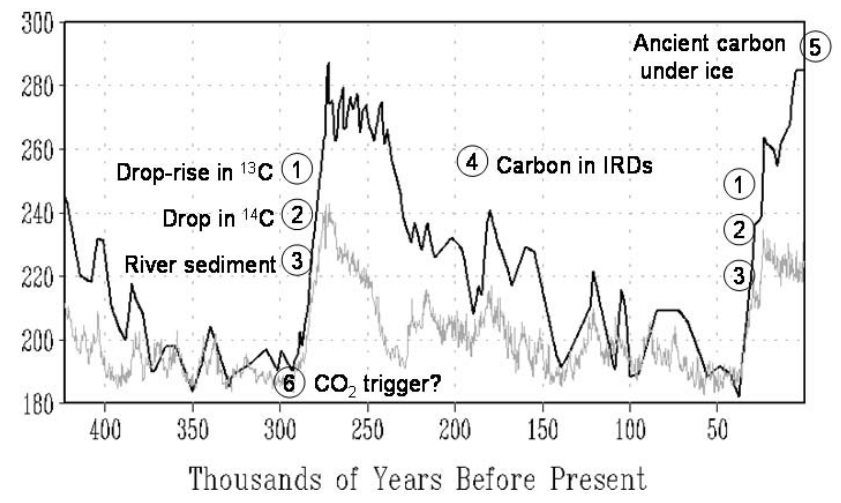

Fig. 6. Some possible consequences of the glacial carbon burial hypothesis. The numbering of events corresponds to the list at the end of the conclusion. The black line is Vostok $\mathrm{CO}_{2}$ in ppmv and the gray line is temperature (deuterium, not labeled).

and represents a major effort in including relevant components with greater details, albeit it is still less than satisfactory for our purpose.

I emphasize that although orbital forcing is not included here so we can isolate a critical positive feedback process not considered before, our findings do not exclude the role of Milankovitch orbital forcing. On the contrary, the above discussion points to the tantalizing possibility that the carbonclimate-icesheet feedback and switch mechanisms identified here interact with orbital forcing in a complex way. In particular, some terminations may be triggered by internal feedbacks, and others by orbital forcing. We should not be discouraged by such complications and shy away from a seemingly complex solution because they nevertheless behave in an understandable way that can be sorted out by an interdisciplinary approach with an open mind for non-conventional possibilities.

To conclude, I summarize a few likely consequences of a land helper scenario driven by the burial and release of terrestrial carbon, as discussed extensively in Sects. 2 and 6. Their observations could support or falsify the glacial burial hypothesis. Some of these have already been shown or speculated but are subject to alternative explanations, such as the deglacial drop-rise transition of $\delta^{13} \mathrm{C}$ and the causality problem at Termination II. But the following list is the natural outcome of the glacial burial hypothesis and the current interactive carbon-climate-icesheet theory. The first three are signatures of glacial burial carbon release during deglaciation whether it is a feedback or a forcing, while the last one concerns the cause-response relationship of climate and $\mathrm{CO}_{2}$ :

1. A deglacial atmospheric $\delta^{13} \mathrm{C}$ drop due to the input of light isotope terrestrial carbon, followed by rise towards high interglacial values due to oceanic effects.

2. A deglacial decrease of atmospheric $\Delta^{14} \mathrm{C}$ of $-100 \%$ o to $-200 \%$ o due to ${ }^{14} \mathrm{C}$-dead burial carbon input. 


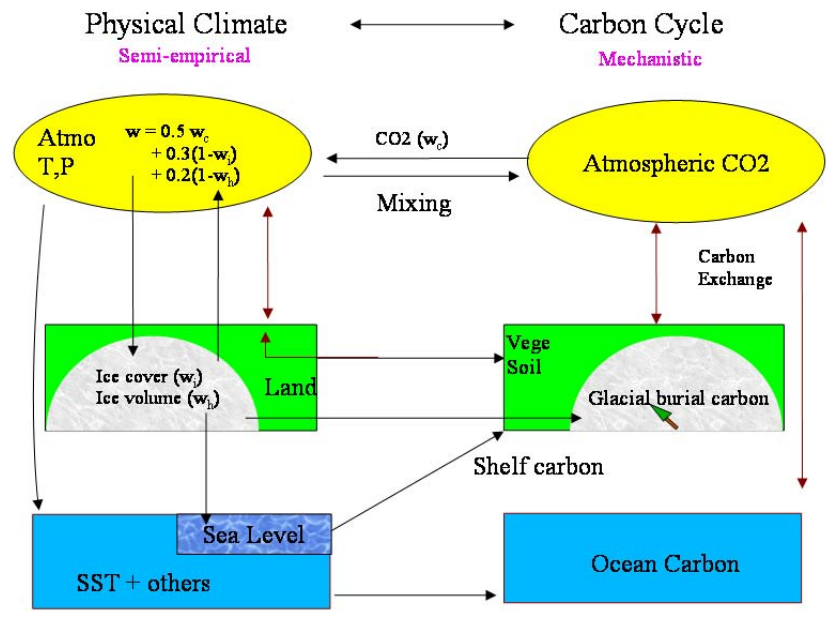

Fig. A1. Schematic diagram of the modeling approach. Note the full interactiveness (prognostic) of physical climate including icesheet and carbon cycle. While the carbon cycle components are process based, the physical climate components are semi-empirical based on GCM time slice simulations and icesheet reconstruction. A large SST change is used as a surrogate for all the other active oceanic mechanisms.

3. A deglacial surge of organic carbon of glacial burial origin in the Mississippi river plume sediments, also possibly the Baltic Sea and St. Lawrence River. At a termination in which $\mathrm{CO}_{2}$ release triggered the deglaciation (below), the initial pulse might slightly lead the change in climate.

4. Organic carbon in the North Atlantic ice-rafted debris (IRDs) associated with the Heinrich events, especially those in the early stages of a glaciation before burial carbon was scourged away by repeated events.

5. Ancient organic carbon buried under the ice caps of the Canadian High Arctic Islands that are melting due to recent warming.

6. Some terminations may have been triggered by the ejection of glacial burial carbon. An initial rise of $\mathrm{CO}_{2}$ would slightly lead temperature, but probably not distinguishable in data so they would appear synchronous, in contrast to a discernable temperature lead in the case of external forcing. These terminations might be those preceded by a long and cold glaciation which would have allowed the buildup of large icesheets. Termination II might be such a candidate.

\section{Appendix A}

\section{Model description}

An Earth system model with balanced complexity in the components has been used to quantify the above theory. By "balanced" I mean that the physical components which are normally much more computationally expensive have significantly reduced complexity to be comparable or less than the carbon components. The physical climate components we use are "semi-empirical" by interpolating GCMsimulated climate time slices (Kutzbach et al., 1998) and reconstructed icesheet distributions for the last $21 \mathrm{ky}$ (Peltier, 1994). The interpolation weighting factor is determined by time-dependent $\mathrm{CO}_{2}$, ice cover and topography. The carbon cycle models for both land and ocean are mechanistic. A schematic diagram of the coupled model is shown in Fig. A1, and the details are discussed below.

\section{A1 Atmosphere}

The semi-empirical atmosphere model is interpolated between an interglacial maximum $(\mathrm{Im})$ and a glacial maximum $(\mathrm{Gm})$. Here the climate simulated by CCM1 (Kutzbach et al., 1998) for the Holocene (6 kBP) is used for Im while the LGM simulation is used for $G m$. A single variable $w(t)$ is used to represent the climate state. For instance, temperature $T(x, t)$ can be computed as a linear interpolation between the two spatially varying extreme states $T_{I m}(x)$ and $T_{G m}(x)$ simulated by CCM1 with $w$ as the weighting factor (The following two equations are the same as in the main text; repeated here for clarity):

$T=w T_{I m}+(1-w) T_{G m}$

where $t$ is time and $x$ represents the spatial dimensions, and $w=w(t)$ is a function of time only. Obviously, this approach does not represent spatial patterns that can not be expressed as linear combinations of the two extreme states. The related error would be larger near the icesheets than in other regions, but its overall effect should be of higher order for interaction with the carbon cycle.

The climate state variable $w$ is determined by three independent factors as:

$w=0.5 w_{c}+0.3\left(1-w_{i}\right)+0.2\left(1-w_{h}\right)$

where $w_{c}$ is the contribution from the greenhouse effect of atmosphere $\mathrm{CO}_{2}, w_{i}(t)$ is due to ice-albedo feedback of the icesheets, and $w_{h}(t)$ is related to atmospheric circulation changes caused by the topographical height of the icesheets. The $\mathrm{CO}_{2}$ factor $w_{c}$ is defined such that its value is larger (thus higher temperature) at higher $\mathrm{CO}_{2}$, while $w_{i}$ and $w_{h}$ are defined such that their values are larger (lower temperature) at more ice cover and higher icesheets. The relative importance of these three factors are $50 \%, 30 \%$, and $20 \%$, based on estimates of the relative roles of greenhouse gases and 
icesheets (Broccoli and Manabe, 1987; Lorius et al., 1990; Weaver et al., 1998). Other factors such as seaice, ocean circulation are fast changing and are treated as part of the physical atmosphere-ocean-land climate system which responds to greenhouse gas and icesheet forcing.

The contribution $w_{c}$ is a function of instantaneous $\mathrm{CO}_{2}$ interpolated between the model's interglacial equilibrium atmospheric $\mathrm{CO}_{2}$ value $\mathrm{CO}_{2}^{i}$ of $272 \mathrm{ppmv}$ and a glacial value $\mathrm{CO}_{2}^{g}$ of 190 ppmv:

$w_{c}=\frac{\mathrm{CO}_{2}-\mathrm{CO}_{2}{ }^{g}}{\mathrm{CO}_{2}{ }^{i}-\mathrm{CO}_{2}{ }^{g}}$

A2 Dynamic vegetation and terrestrial carbon

The terrestrial carbon model Vegetation-GlobalAtmosphere-Soil (VEGAS) simulates the dynamics of vegetation growth and competition among different plant functional types (PFTs). It includes 4 PFTs: broadleaf tree, needleleaf tree, cold grass, and warm grass. The different photosynthetic pathways are distinguished for $\mathrm{C} 3$ (the first three PFTs above) and C4 (warm grass) plants. Photosynthesis is a function of light, temperature, soil moisture and $\mathrm{CO}_{2}$. Accompanying the vegetation dynamics is the full terrestrial carbon cycle starting from the allocation of the photosynthetic carbon into three vegetation carbon pools: leaf, root, and wood. After accounting for respiration, the biomass turnover from these three vegetation carbon pools cascades into a fast, an intermediate and finally a slow soil pool. Temperature and moisture dependent decomposition of these carbon pools returns carbon back into atmosphere, thus closes the terrestrial carbon cycle. A decreasing temperature dependence of respiration from fast to slow soil pools takes into account the effects of physical protection of organic carbon by soil particles below ground. The vegetation component is coupled to land and atmosphere through a soil moisture dependence of photosynthesis and evapotranspiration, as well as dependence on temperature, radiation, and atmospheric $\mathrm{CO}_{2}$. The isotope ${ }^{13} \mathrm{C}$ is modeled by assuming a different carbon discrimination for $\mathrm{C} 3$ and $\mathrm{C} 4$ plants, thus providing a diagnostic quantity useful for distinguishing ocean and land sources and sinks of atmospheric $\mathrm{CO}_{2}$. Competition between $\mathrm{C} 3$ and $\mathrm{C} 4$ grass is a function of temperature and $\mathrm{CO}_{2}$ following Collatz et al. (1998).

The dynamic vegetation model is coupled to a physical land-surface model Simple-Land (SLand) (Zeng et al., 2000) which provides soil moisture and temperature, while evapotranspiration is coupled to the photosynthesis component of the vegetation model.

\section{A3 Ocean}

As noted above, factors such as seaice, ocean circulation are fast changing and are treated as part of the physical atmosphere-ocean-land climate system which responds to greenhouse gas and icesheet forcing, and they are therefore represented by the interpolation in the atmospheric model above. Since we are concerned about the interaction between carbon cycle and climate, we only need to represent the effects on carbon cycle of changes in the physical climate system.

A sea surface temperature anomaly $T_{o}$ (relative to $I m$ ) is slaved to the atmosphere with a time delay of $\tau_{o}=100 \mathrm{y}$ :

$\frac{d T_{o}}{d t}=\frac{(1-w) T_{o}^{g}-T_{o}}{\tau_{o}}$

where $T_{o}^{g}=-6 K$ is maximum glacial cooling. Zeng (2003) showed that a $4 \mathrm{~K}$ cooling in the ocean carbon model SUE leads to about 30 ppmv Im to $G m$ change, similar to a coolerthan-CLIMAP scenario supported by recent studies (Ridgwell, 2001). Since it is beyond the scope here to include all the ocean mechanisms, a change of ocean temperature by $6 \mathrm{~K}$ was chosen as a surrogate to obtain a total ocean-driven change of about 55 ppmv, a value on the low side of which the major oceanic mechanisms can explain.

The ocean carbon cycle model SUE (Ridgwell, 2001) simulates both the ocean $\mathrm{CO}_{2}$ mixing and $\mathrm{CaCO}_{3}$ sediment dissolution processes, as well as ${ }^{13} \mathrm{C}$. The version used here consists of 16 horizontal regions covering the major oceanic sub-basins and 8 layers in the vertical, forced by the fields of modern circulation, salinity, etc. All the active changes on glacial-interglacial cycles are represented by changes in sea surface temperature as discussed above.

A major caveat is that this approach will not resolve significant timing differences of different ocean $\mathrm{CO}_{2}$ mechanisms. For instance, the earlier $\mathrm{CO}_{2}$ release may be caused by glacial dust fertilization while the sea-level related changes such as coral reef hypothesis would occur several thousand years later. Ocean surface temperature changes took place throughout deglaciation, thus piggybacking the other active ocean changes on it should capture the overall effects. Future research will include other active ocean mechanisms in a more realistic way. It is worth noting that, the passive oceanic buffering effects in response to terrestrial changes are always considered, including the multiple time scales associated with deep ocean circulation and sediment carbonate compensation.

\section{A4 Icesheet dynamics}

This semi-empirical model is not mechanistic, but nonetheless represents several major icesheet processes such as the asymmetry in time scale during decay and growth, and is constrained by the observed changes over the last $21 \mathrm{ky}$. Overall it is similar but slightly more sophisticated than that of Imbrie and Imbrie (1980), in particular the weighting factors are used to interpolate the spatial patterns of ice distribution. 
Ice cover change is assumed to follow temperature change with a delay of $\tau_{i}=100 y$ :

$\frac{d w_{i}}{d t}=\frac{1-w-w_{i}}{\tau_{i}}$

The weighting factor $w_{i}$ could then be used to interpolate the ice cover. However, unlike the straightforward interpolation for temperature and precipitation (which can also be extrapolated), ice cover is either 0 or 1 . Ice cover "interpolation" is therefore done by spreading (glaciation) or shrinking (deglaciation) the ice cover data (Peltier, 1994) at $1 \mathrm{ky}$ time resolution based on the information of $w_{i}$. Thus the Laurentide icesheet can not spread further south than at LGM even if the climate gets cooler. Another consequence of these lower and upper limits on icesheet is that when climate is outside the LGM and Holocene bound ( $w$ less than 0 or great than 1), further climate change will come only from $\mathrm{CO}_{2}$ greenhouse effect. This is a limitation of the semi-empirical model but not a major drawback as the model will be applied only to the Pleistocene when LGM was the coldest period. On the warmer side, since Antarctica and Greenland had no major change in ice-covered area during Pleistocene, only regions such as the high arctic Canadian islands may have changed significantly but their small area should not have a major impact on our results. In addition, as a posteriori justification, the model simulated a $\mathrm{CO}_{2}$ range of $190-280 \mathrm{ppmv}$, so that the interpolation is only slightly out of range on the warm side because $w_{c}$ is interpolated using $\mathrm{CO}_{2}$ range of 190272 ppmv (Eq. A3).

Once a place is ice covered, ice thickness $h(x)$ grows linearly towards a potential value $w_{i} h_{\max }$ at a time scale $\tau_{h}$ :

$\frac{d h}{d t}=\frac{w_{i} h_{\max }}{\tau_{h}}$

where $h_{\max }(x)$ is the ice thickness of the difference of the observed LGM and Holocene values (Peltier, 1994), and $\tau_{h}$ (in ky) is:

$$
\tau_{h}= \begin{cases}4, & \text { ice decay } \\ 15\left(1-w_{h}\right)+40 w_{h}, & \text { ice growth }\end{cases}
$$

Whether the icesheets are in a decay or growth phase depends on whether global ice volume is decreasing or increasing (below). Furthermore, if ice cover becomes zero at any specific place, ice thickness is immediately set to zero. Icesheet melting is fast during decay, thus the $4 \mathrm{ky}$ time scale. The icesheet growth is set between $15 \mathrm{ky}$ and $40 \mathrm{ky}$ with slower rate at higher icesheet to account for the fact that snowfall decreases at higher altitude. The timescales, both at growth and decay, represents the rates at maximum climate forcing so that the actual glaciation and deglaciation would take longer. And not surprisingly, the duration of the simulated glacial-interglacial cycles are sensitive to especially the growth time scales.

The ice topography factor $w_{h}$ is defined as relative ice volume.

$w_{h}=V_{i} / V_{i \max }$ where $V_{i}$ is the ice volume of the changing icesheets, i.e., a spatial integral of ice thickness $h$, while $V_{i \max }$ is its maximum value. Note that these are all changes relative to an interglacial value so that $w_{h}$ goes from 0 to 1 when ice grows from interglaical to glacial maximum. Sea level change is also proportional to $w_{h}$, thus influencing continental shelf carbon. Then icesheet topography (altitude at the surface of the icesheet) relative to sea level $h_{s}(x)$ is computed as:

$h_{s}=h_{s \min }+\left(h_{s \max }-h_{s \min }\right) w_{h}$

where $h_{s \max }(x)$ and $h_{s \min }(x)$ are the observed height at LGM and Holocene (Peltier, 1994), respectively.

\section{A5 Subglacial transport of organic carbon}

When icesheet grows to substantial height, subglacial basal flow becomes significant, especially when melting occurs at the base. The transport of glacial burial carbon is at the center of the current theory. However, the processes of subglacial transport of sediment are poorly understood, and processbased modeling is being attempted only very recently (Hildes et al., 2004).

Besides large-scale ice flow, several mechanisms could act to flush out organic carbon buried under the icesheets at the height of glacial maximum. One such mechanism is through streams of meltwater at the base of an icesheet, as evidenced by eskers left behind by the great Northern Hemisphere icesheets. Another mechanism involves the fast moving ice streams (MacAyeal, 1993) which could be very efficient at transporting and exposing large amount of carbon already near the edge of an icesheet. Many other icesheet instability mechanisms may also play a role. In the absence of better understanding and availability of modeling tool, a rather simple treatment is used here, with the caveat that it may not capture the details accurately of deglacial burial carbon release and the differences from termination to termination.

Transport of glacial sediment including burial carbon is modeled as:

$v=-C_{s l} h\left|\nabla h_{s}\right|^{2} \nabla h_{s}+v_{0}$

where $v$ is the velocity at the ice-sediment boundary, and the full vertical profile is assumed quadratic with $v$ as the top boundary condition and zero as the lower sediment-bedrock boundary condition. The first term on the rhs is a large-scale flow (Greve, 1997), and the second term $v_{0}$ represents additional transport at deglaciation of the burial organic carbon towards the edge of the icesheets at a speed increasing from zero to $8 \times 10^{-6} \mathrm{~m} \mathrm{~s}^{-1}\left(250 \mathrm{~m} \mathrm{y}^{-1}\right)$ within 3000 years. The transport $v_{0}$ is important for the model behavior, as the speed at which the glacial burial carbon is transported out of the icesheet (therefore how fast it is released back into the atmosphere) is critical for initiating the positive feedbacks at deglaciation. The transport starts when ice volume grows to the maximum value $\left(w_{h}=1\right)$. This also signals the beginning 
of deglaciation (Fig. 4). The quantitative treatment here is best viewed as an assumption, or at most a highly simplified representation rather than detailed mechanistic prediction.

After the burial carbon being re-exposed to the atmosphere, it is decomposed at a time scale of 100 year at $25^{\circ} \mathrm{C}$ and slower at lower temperature.

\section{A6 Treatment of carbon on continental shelves}

During the glacial-interglacial cycles, sea level rises and falls as water is drawn to form ice on land and vise versa. Sea level is proportional to ice volume factor $w_{h}$, and a land-sea mask is determined at each time step according to the topographical information $h_{s}$ above. The continental shelf area exposed at lower sea level grows vegetation and accumulates carbon, modeled dynamically as climate changes. The shelf carbon was subsequently submerged and released back into the atmosphere at deglaciation. The time scale for the decomposition of the submerged carbon was set at $300 \mathrm{y}$ at $25^{\circ} \mathrm{C}$.

Acknowledgements. I am grateful to W. Ruddiman for his encouragement in my persue of a non-conventional idea. I thank N. Diffenbaugh and a reviewer for pointing out the possibility of an atmospheric C14 fingerprint, and M. Huber and D. Kirk-Davidoff for that of ice rafted debris. I also benefitted from communications with J. Adams, J. Sarmiento, K. Matsumoto, R. F. Anderson and H. Spero. Comments from three anonymous reviewers prompted me to write Sect. 2 and expand on discussion and conclusion sections, thus helped to improve the paper significantly. The ocean carbon model was kindly provided by A. Ridgwell. I am indebted to the hospitality and computing support from the Italian National Agency for Energy and Environment (ENEA), where most of this research was conducted during several summer visits. The project was in part supported by NSF Climate Dynamics Program, NOAA CLIVAR-Atlantic Program, and NOAA Global Carbon Cycle Program.

Edited by: J. Hargreaves

\section{References}

Adams, J. M., Faure, H., Faure-Denard, L., McGlade, J. M., et al.: Increase in terrestial carbon storage from the last glacial maximum to the present, Nature, 348, 711-714, 1990.

Archer, D., Kheshgi, H., and Maier-Reimer, E.: Multiple timescales for neutralization of fossil fuel CO2, Geophys. Res. Lett., 24(4), 405-408, 1997.

Archer, D., Winguth, A., Lea, D., and Mahowald, N.: What caused the glacial/interglacial atmospheric $\mathrm{pCO}(2)$ cycles?, Rev. Geophys., 38, 159-189, 2000.

Broccoli, A. J. and Manabe, S.: The influence of continental ice, atmospheric $\mathrm{CO} 2$, and land albedo on the climate of the last glacial maximum, Clim. Dyn., 1, 87-99, 1987.

Broecker, W. S. and Henderson, G. M.: The sequence of events surrounding Termination II and their implications for the cause of glacial-interglacial CO2 changes, Paleoceanography, 13, 352$364,1998$.
Caillon, N., Severinghaus, J. P., Jouzel, J., et al.: Timing of atmospheric $\mathrm{CO} 2$ and Antarctic temperature changes across termination III, Science, 299(5613), 1728-1731, 2003.

Caspersen, J. P., Pacala, S. W., Jenkins, J. C., et al.: Contributions of land-use history to carbon accumulation in US forests, Science, 290(5494), 1148-1151, 2000.

Collatz, G. J., Berry, J. A., and Clark, J. S.: Effects of climate and atmospheric $\mathrm{CO} 2$ partial pressure on the global distribution of C-4 grasses: present, past, and future, Oecologia, 114, 441-454, 1998.

Crowley, T. J.: Potential reconciliation of Devil's Hole and deep-sea Pleistocene Chronologies, Paleoceanography, 9(1), 1-5, 1994.

Crowley, T. J.: Ice age terrestrial carbon changes revisited, Global Biogeochem. Cycle, 9, 377-389, 1995.

Crowley, T. J.: Cycles, cycles everywhere, Science, 295(5559), 1473-1474, 2002.

Curry, W. B., Duplessy, J.-C., Labeyrie, L. D., and Shackleton, N. $\mathrm{J}$. : Changes in the distribution of $\delta^{13} \mathrm{C}$ of deep water $\mathrm{CO} 2$ between the last glacial and the Holocene, Paleoceanography, 3, 317-341, 1988.

Dredge, L. A., Morgan, A. V., and Nielsen, E.: Sangamon and presangamon interglaciations in the Hudson-Bay lowlands of Manitoba, Geographie Physique Et Quaternarie, 44, 319-336, 1990.

Duplessy, J.-C., Shackleton, N. J., Fairbanks, R. J., Labeyrie, L. D., Oppo, D., and Kallel, N.: Deep water source variations during the last climatic cycle and their impact on the global deep water circulation, Paleoceanography, 3, 343-360, 1988.

Edwards, R. L., Cheng, H., Murrell, M. T., et al.: Protactinium-231 dating of carbonates by thermal ionization mass spectrometry: Implications for quaternary climate change, Science, 276(5313), 782-786, 1997.

EPICA community members: Eight glacial cycles from an Antarctic ice core, Nature, 429, 623-628, 2004.

Field, C. B.: Plant physiology of the "missing" carbon sink, Plant Physiology, 125, 25-28, 2001.

Flint, R. F.: Growth of North America Ice Sheet during the Wisconsin Age, Geol. Soc. Am. Bull., 54, 325-362, 1943.

Franzen, L. G.: Are wetlands the key to the ice-age cycle enigma, Ambio, 23, 300-308, 1994.

Franzen, L. G., Chen, D. L., and Klinger, L. F.: Principles for a climate regulation mechanism during the late phanerozoic era, based on carbon fixation in feat-forming wetlands, Ambio, 25(7), 435-442, 1996.

Forsstrom, L. and Punkari, M.: Initiation of the last glaciation in Northern Europe, Quaternary Sci. Rev., 16(10), 1197-1215, 1997.

Friedlingstein, P., Cox, P., Betts, R., Bopp, L., von Bloh, W., Brovkin, V., Cadule, P., Doney, S., Eby, M., Fung, I., Bala, G., John, J., Jones, C., Joos, F., Kato, T., Kawamiya, M., Knorr, W., Lindsay, K., Matthews, H. D., Raddatz, T., Rayner, P., Reick, C., Roeckner, E., Schnitzler, K.-G., Schnur, R., Strassmann, K., Weaver, A. J., Yoshikawa, C., and Zeng, N.: Climate-Carbon Cycle Feedback Analysis: Results from the C4MIP Model Intercomparison, J. Climate, 19, 3337-3353, 2006.

Gallup, C. D., Cheng, H., Taylor, F. W., et al.: Direct determination of the timing of sea level change during termination II, Science, 295(5553), 310-313, 2002.

Gildor, H. and Tziperman, E.: Physical mechanisms behind biogeochemical glacial-interglacial $\mathrm{CO} 2$ variations, Geophys. Res. 
Lett., 28(12), 2421-2424, 2001.

Greve, R.: A continuum-mechanical formulation for shallow polythermal icesheets, Phil. Trans. R. Soc. Lond., A, 355, 921-974, 1997.

Hays, J. D., Imbrie, J., and Shackleton, N. J.: Variations in the Earth's orbit: Pacemakers of the ice ages, Science, 194, 11211132, 1976.

Hildes, D. H. D., Clarke, G. K. C., Flowers, G. E., and Marshall, S. J.: Subglacial erosion and englacial sediment transport modelled for North American ice sheets, Quaternary Sci. Rev., 23(3), 409430, 2004.

Herbert, T. D., Schuffert, J. D., Andreasen, D., et al.: Collapse of the California Current during glacial maxima linked to climate change on land, Science, 293(5527), 71-76, 2001.

Hughen, K. A., Southon, J. R., Lehman, S. J., et al.: Synchronous radiocarbon and climate shifts during the last deglaciation, Science, 290(5498), 1951-1954, 2000.

Hughen, K., Lehman, S., Southon, J., et al.: C-14 activity and global carbon cycle changes over the past 50,000 years, Science, 303(5655), 202-207, 2004.

Imbrie, J. and Imbrie, J. Z.: Modeling the climatic response to orbital variations, Science, 207, 943-953, 1980.

Imbrie, J., Berger, A., Boyle, E. A., et al.: On the Structure and origin of major glaciation cycles. 2. The 100,000-year cycle, Paleoceanography, 8(6), 699-735, 1993.

Imbrie, J., Mix, A. C., and Martinson, D. G.: Milankovitch theory viewed from Devil's Hole, Nature, 363(6429), 531-533, 1993.

Kageyama, M., Peyron, O., Pinot, S., et al.: The Last Glacial Maximum climate over Europe and western Siberia: a PMIP comparison between models and data, Clim. Dyn., 17(1), 23-43, 2001.

Kaplan, J. O., Prentice, I. C., Knorr, W., et al.: Modeling the dynamics of terrestrial carbon storage since the Last Glacial Maximum, Geophys. Res. Lett., 29(22), 2074, doi:10.1029/2002GL015230, 2002.

Keir, R. S.: Is there a component of Pleistocene $\mathrm{CO} 2$ change associated with carbonate dissolution cycles?, Paleoceanography, 10, 871-880, 1995.

Kirschbaum, M. U. F.: The temperature-dependence of soil organicmatter decomposition, and the effect of global warming on soil organic-C storage, Soil Biol. Biochem., 27(6), 753-760, 1995.

Kleman, J. and Hattestrand, C.: Frozen-bed Fennoscandian and Laurentide ice sheets during the Last Glacial Maximum, Nature, 402(6757), 63-66, 1999.

Klinger, L. F.: Peatland formation and ice ages: A possible Gaian mechanism related to community succession, in: Scientists on Gaia, edited by: Schneider, S. H. and Boston, P. J., pp. 247-255, MIT press, Cambridge, Mass., 1991.

Klinger, L. F., Taylor, J. A., and Franzen, L. G.: The potential role of peatland dynamics in ice-age initiation, Quaternary Res., 45(1), 89-92, 1996.

Koehler, P., Fischer, H., Munhoven, G., and Zeebe, R. E.: Quantitative interpretation of atmospheric carbon records over the last glacial termination, Global Biogeochem. Cycles, 19, GB4020, doi:10.1029/2004GB002345, 2005.

Koehler, P. and Fischer, H.: Simulating low frequency changes in atmospheric CO2 during the last 740000 years, Clim. Past, 2, 57-78, 2006, http://www.clim-past.net/2/57/2006/.

Kutzbach, J., Gallimore, R., Harrison, S., Behling, P., et al.: Climate and biome simulations for the past 21,000 years, Quaternary Sci. Rev., 17, 473-506, 1998.

Laj, C., Kissel, C., Mazaud, A., et al.: Geomagnetic field intensity, North Atlantic Deep Water circulation and atmospheric delta$14 \mathrm{C}$ during the last $50 \mathrm{kyr}$, Earth Planet. Sci. Lett., 200, 177-190, 2002.

Lea, D. W., Bijma, J., Spero, H. J., and Archer, D.: Implications of a carbonate ion effect on shell carbon and oxygen isotopes for glacial ocean conditions, in: Use of Proxies in Paleoceanography: Examples from the South Atlantic, edited by: Fischer, G. and Wefer, G., Springer-Verlag, Berlin Heidelberg, pp. 513-522, 1999.

Leuenberger, M. C., Eyer, M., Bogni, S., Elsig, J., and Stocker, T. F.: High resolution $\delta^{13} \mathrm{C}$ measurements from the EPICA Dome $\mathrm{C}$ ice core, Proceedings of the 7th International $\mathrm{CO} 2$ Conference, 659-660, Sep. 25-30, Boulder, Colorado, USA, 2005.

Li, X. S., Berger, A., and Loutre, M. F.: CO2 and northern hemisphere ice volume variations over the middle and late Quaternary, Clim. Dyn., 14(7-8), 537-544, 1998.

Lorius, C., Jouzel, J., Raynaud, D., et al.: The ice-core record - climate sensitivity and future greenhouse warming, Nature, 347(6289), 139-145, 1990.

Luo, Y. Q., Hui, D. F., and Zhang, D. Q.: Elevated CO2 stimulates net accumulations of carbon and nitrogen in land ecosystems: A meta-analysis, Ecology, 87(1), 53-63, 2006.

MacAyeal, D. R.: Binge/purge oscillations of the Laurentide Ice Sheet as a cause of the North Atlantic Heinrich events, Paleoceanography, 8, 775-784, 1993.

Marino, B. D., McElroy, M. B., Salawitch, R. J., and Spaulding, W. G.: Glacial-to-interglacial variations in the carbon isotopic composition of atmospheric CO2, Nature, 357, 461-466, 1992.

Marshall, S. and Clark, P.: Basal temperature evolution of North American ice sheets and implications for the 100-kyr cycle, Geophys. Res. Lett., 29, doi:10.1029/2002GL015192, 2002.

Matsumoto, K. and Lynch-Stieglitz, J.: Similar glacial and Holocene deep water circulation inferred from southeast Pacific benthic foraminiferal carbon isotope composition, Paleoceanography, 14(2), 149-163, 1999.

Oerlemans, J.: Model experiments on the 100,000-yr glacial cycle, Nature, 287, 430-432, 1980.

Otto, D., Rasse, D., Kaplan, J., et al.: Biospheric carbon stocks reconstructed at the Last Glacial Maximum: comparison between general circulation models using prescribed and computed sea surface temperatures, Global Planet. Change, 33, 117-138, 2002.

Pacala, S. W., Hurtt, G. C., Baker, D., et al.: Consistent land- and atmosphere-based US carbon sink estimates, Science, 292(5525), 2316-2320, 2001.

Paillard, D. and Parrenin, F.: The Antarctic ice sheet and the triggering of deglaciations, Earth Planet. Sci. Lett., 227(3-4), 263-271, 2004.

Peltier, W. R.: Ice age paleotopography, Science, 265, 195-201, 1994.

Petit, J. R., Jouzel, J., Raynaud, D., Barkov, N. I., et al.: Climate and atmospheric history of the past 420,000 years from the Vostok ice core, Antarctica, Nature, 399, 429-436, 1999.

Punkari, M. and Forsstrom, L.: Organic remains in Finnish subglacial sediments, Quaternary Res., 43(3), 414-425, 1995.

Ridgwell, A. J., Watson, A. J., and Raymo, M. E.: Is the spectral signature of the $100 \mathrm{kyr}$ glacial cycle consistent with a Mi- 
lankovitch origin?, Paleoceanography, 14(4), 437-440, 1999.

Ridgwell, A. J.: Glacial-interglacial perturbations in the global carbon cycle, Ph.D thesis, Univ. of East Anglia at Norwich, UK, available at http://tracer.env.uea.ac.uk/e114/ridgwell_2001. pdf, 2001.

Roe, G. H. and Allen, M. R.: A comparison of competing explanations for the 100,000-year ice age cycle, Geophys. Res. Lett., 26(15), 2259-2262, doi:10.1029/1999GL900509, 1999.

Ruddiman, W. F.: Orbital insolation, ice volume, and greenhouse gases, Quat. Sci. Rev., 22(15-17), 1597-1629, 2003.

Saltzman, B. and Maasch, K. A.: Carbon cycle instability as a cause of the late Pleistocene ice age oscillations: Modeling the asymmetric response, Global Biogeochem. Cycles, 2(2), 177$185,1988$.

Sarmiento, J. L. and Gruber, N.: Sinks for anthropogenic carbon, Physics Today, 55(8), 30-36, 2002.

Shackleton, N. J.: Carbon-13 in Uvigerina: Tropical rainforest history and the equatorial Pacific carbonate dissolution cycles, in: The Fate of Fossil Fuel CO2 in the Oceans, edited by: Andersen, N. R. and Malahoff, A., pp. 401-428, Plenum, New York, 1977.

Shackleton, N. J.: The 100,000-year ice-age cycle identified and found to lag temperature, carbon dioxide, and orbital eccentricity, Science, 289(5486), 1897-1902, 2000.

Sigman, D. M. and Boyle, E. A.: Glacial/interglacial variations in atmospheric carbon dioxide, Nature, 407, 859-869, 2000.

Toggweiler, J. R., Russell, J. L., and Carson, S. R.: Midlatitude westerlies, atmospheric $\mathrm{CO} 2$, and climate change during the ice ages, Paleoceanography, 21(2), art. no. PA2005, 2006.

Toggweiler, J. R.: Variation of atmospheric $\mathrm{CO} 2$ by ventilation of the ocean's deepest water, Paleoceanography, 14(5), 571-588, 1999.

Skidmore, M. L., Foght, J. M., and Sharp, M. J.: Microbial life beneath a high Arctic glacier, Appl. Environ. Microbiol., 66(8), 3214-3220, 2000.

Smith, H. J., Fischer, H., Wahlen, M., Mastroianni, D., et al.: Dual modes of the carbon cycle since the Last Glacial Maximum, Nature, 400, 248-250, 1999.

Smith, L. C., MacDonald, G. M., Velichko, A. A., Beilman, D. W., Borisova, O. K., Frey, K. A., Kremenetski, K. V., and Sheng, Y.: Siberian peatlands a net carbon sink and global methane source since the early Holocene, Science, 303, 353-356, 2004.

Souchez, R.: The buildup of the ice sheet in central Greenland, J. Geophys. Res., 102(C12), 26317-26323, 1997.

Spero, H. J., Bijma, J., Lea, D. W., and Bemis, B. E.: Effect of seawater carbonate concentration on foraminiferal carbon and oxygen isotopes, Nature, 390(6659), 497-500, 1997.
Spero, H. J. and Lea, D. W.: The cause of carbon isotope minimum events on glacial terminations, Science, 296, 522-525, 2002.

Thompson, L. G.: Tropical ice core evidence for rapid Holocene climate change and asynchronous glaciation (Emiliani Lecture), Eos Trans. AGU, 85(47), Fall Meet. Suppl., Abstract PP33C-01, 2004.

Vettoretti, G. and Peltier, W. R.: Sensitivity of glacial inception to orbital and greenhouse gas climate forcing, Quaternary Sci. Rev., 23(3-4), 499-519, 2004.

Vitousek, P. M.: Nutrient Cycling and Limitation: Hawai'i as a Model System, Princeton University Press, 232pp, 2004.

Weaver, A. J., Eby, M., Augustus, F. F., et al.: Simulated influence of carbon dioxide, orbital forcing and ice sheets on the climate of the Last Glacial Maximum, Nature, 394(6696), 847-853, 1998.

Weitemeyer, K. A. and Buffett, B. A.: Accumulation and release of methane from clathrates below the Laurentide and Cordilleran ice sheets, Global and Planetary Change, 53(3), 176-187, 2006.

Welker, J. M., Fahnestock, J. T., and Jones, M. H.: Annual CO2 flux in dry and moist arctic tundra: Field responses to increases in summer temperatures and winter snow depth, Climatic Change, 44(1-2), 139-150, 2000.

Winograd, I. J., Coplen, T. B., Landwehr, J. M., et al.: Continuous 500,000 -year climate record from vein calcite in Devils-Hole, Nevada, Science, 258(5080), 255-260, 1992.

Wunsch, C.: Quantitative estimate of the Milankovitch-forced contribution to observed Quaternary climate change, Quat. Sci. Rev., 23(9-10), 1001-1012, 2004.

Yves, J. D.: Indications of recent extensive glacierization in northcentral Baffin Island, N. W. T., J. Glacial., 4, 197-205, 1962.

Zeng, N., Neelin, J. D., and Chou, C.: A quasi-equilibrium tropical circulation model - implementation and simulation, J. Atmos. Sci., 57, 1767-1796, 2000.

Zeng, N.: Glacial-Interglacial Atmospheric CO2 Changes - The Glacial Burial Hypothesis, Adv. Atmos. Sci., 20, 677-693, 2003.

Zeng, N., Qian, H., Munoz, E., and Iacono, R.: How strong is carbon cycle-climate feedback under global warming?, Geophys. Res. Lett., 31, L20203, doi:10.1029/2004GL020904, 2004.

Zeng, N., Mariotti, A., and Wetzel, P.: Terrestrial mechanisms of interannual $\mathrm{CO} 2$ variability, Global Biogeochem. Cycle, 19, GB1016, doi:10.1029/2004GB002273, 2005.

Zimov, S. A., Schuur, E. A. G., and Chapin, F. S.: Permafrost and the global carbon budget, Science, 312(5780), 1612-1613, 2006. 